\title{
Priming astrocytes with TNF enhances their susceptibility to Trypanosoma cruzi infection and creates a self-sustaining inflammatory milieu
}

Andrea Alice Silva ${ }^{1,2+}$, Rafael Rodrigues Silva ${ }^{1,5+}$, Daniel Gibaldi ${ }^{1}$, Rafael Meyer Mariante ${ }^{3}$, Jessica Brandão dos Santos ${ }^{1}$, Isabela Resende Pereira ${ }^{1,6}$, Otacílio Cruz Moreira ${ }^{4}$ and Joseli Lannes-Vieira ${ }^{1 *}$

\begin{abstract}
Background: In conditions of immunosuppression, the central nervous sty 5ystem (CNS) is the main target tissue for the reactivation of infection by Trypanosoma cruzi, the causative agent of Chagas disease. In experimental $T$. cruzi infection, interferon gamma (IFNY) ${ }^{+}$microglial cells surround astrocytes harboring amastigote parasites. In vitro, IFNY fuels astrocyte infection by T. cruzi, and IFNY-stimulated infected astrocytes are implicated as potential sources of tumor necrosis factor (TNF). Pro-inflammatory cytokines trigger behavioral alterations. In T. cruzi-infected mice, administration of anti-TNF antibody hampers depressive-like behavior. Herein, we investigated the effects of TNF on astrocyte susceptibility to $T$. cruzi infection and the regulation of cytokine production.

Methods: Primary astrocyte cultures of neonatal C57BL/6 and C3H/He mice and the human U-87 MG astrocyte lineage were infected with the Colombian T. cruzi strain. Cytokine production, particularly TNF, and TNF receptor 1 (TNFR1/p55) expression were analyzed. Recombinant cytokines (rIFNy and rTNF), the anti-TNF antibody infliximab, and the TNFR1 modulator pentoxifylline were used to assess the in vitro effects of TNF on astrocyte susceptibility to T. cruzi infection. To investigate the role of TNF on CNS colonization by T. cruzi, infected mice were submitted to anti-TNF therapy.

Results: rTNF priming of mouse and human astrocytes enhanced parasite/astrocyte interaction (i.e., the percentage of astrocytes invaded by trypomastigote parasites and the number of intracellular parasite forms/astrocyte). Furthermore, T. cruzi infection drove astrocytes to a pro-inflammatory profile with TNF and interleukin-6 production, which was amplified by rTNF treatment. Adding rTNF prior to infection fueled parasite growth and trypomastigote egression, in parallel with increased TNFR1 expression. Importantly, pentoxifylline inhibited the TNF-induced increase in astrocyte susceptibility to T. cruzi invasion. In T. cruzi-infected mice, anti-TNF therapy reduced the number of amastigote nests in the brain.

Conclusions: Our data implicate TNF as a promoter of T. cruzi invasion of mouse and human astrocytes. Moreover, the TNF-enriched inflammatory milieu and enhanced TNFR1 expression may favor TNF signaling, astrocyte colonization by T. cruzi and egression of trypomastigotes. Therefore, in T. cruzi infection, a self-sustaining TNF-induced inflammatory circuit may perpetuate the parasite cycle in the CNS and ultimately promote cytokine-driven behavioral alterations.
\end{abstract}

Keywords: Tumor necrosis factor, Chagas disease, Pentoxifylline, Anti-TNF antibody Infliximab, TNFR1

\footnotetext{
* Correspondence: lannes@ioc.fiocruz.br; joselilannes@gmail.com

${ }^{\dagger}$ Equal contributors

'Laboratório de Biologia das Interações, Instituto Oswaldo Cruz - Fiocruz, Av.

Brasil 4365, Rio de Janeiro, RJ 21040-360, Brazil

Full list of author information is available at the end of the article
} 


\section{Background}

Astrocytes are heterogeneous cells that are involved in maintaining the homeostatic environment in the central nervous system (CNS) [1]. They are the most abundant cell type in the brain and play an important role in several infectious and inflammatory diseases [2-5]. Like microglia and neurons, astrocytes can produce inflammatory mediators such as chemokines and cytokines, including the potent pro-inflammatory tumor necrosis factor (TNF), in response to intrinsic and extrinsic insults $[6,7]$. TNF binds to two different receptors, TNFR1 (p55) and TNFR2 (p75), and mediates various biological responses in cells bearing these receptors [8, 9]. Astrocytes constitutively express Tnfr1 mRNA and nearly undetectable Tnfr 2 mRNA, neither of which are upregulated after exposure to interferon gamma (IFNY) or TNF [10]. TNF and interleukin (IL)-6, another pro-inflammatory cytokine, are positively correlated with the rate of neuronal apoptosis in the CNS and with neurodegeneration $[11,12]$. Increased TNF levels have been associated with neuropathology in animal models of sleeping sickness, a human disease induced by infection with the extracellular parasite Trypanosoma brucei, and malaria, caused by Plasmodium sp. [13-15]. Indeed, TNF dysregulation has been associated with blood-brain barrier abnormalities and the initiation of CNS inflammation and pathology in non-infectious and infectious diseases [16]. However, the effect of TNF in the CNS during Trypanosoma cruzi infection is unclear. This intracellular protozoan parasite is the etiologic agent of Chagas disease, a neglected tropical disease characterized by a systemic inflammatory response enriched in TNF in chronic patients [17, 18] and experimental models [19].

In the acute phase of $T$. cruzi infection, particularly in infants and susceptible experimental mice, intense meningoencephalitis and accumulation of amastigote forms of the parasite inside glial cells are common, but CNS inflammation and parasitism are drastically reduced in the chronic phase [20-29]. Nevertheless, in chronic $T$. cruzi infection, neurological involvement is observed in 75-90\% of human immunodeficiency virus (HIV)-coinfected patients and in individuals immunocompromised by cancer, suppressive treatment, organ transplantation, or malnourishment $[30,31]$. In these situations, the most common findings are neurological abnormalities, recrudescence of parasitemia, and parasite detection in the brain tissue and cerebrospinal fluid [21, 24, 30]. In early diagnosed patients, the signs of CNS impairment disappear after treatment with the trypanocidal drug benznidazole [22-24]. In chronically infected individuals, reactivation of $\mathrm{CNS}$ parasitism may occur via the reentry of blood circulating parasites; CNS invasion by inflammatory cells carrying parasite, likewise the macrophages carrying HIV by a Trojan horse mechanism [32]; or increase of low-grade CNS parasitism. In chronically T. cruzi-infected $\mathrm{C} 3 \mathrm{H} / \mathrm{He}$ mice undergoing immunosuppression, reactivation of infection with numerous and large parasite nests and inflammation is restricted to the CNS and occurs in the absence of parasitemia, supporting the existence of low-grade parasite persistence in CNS-resident cells [27]. Nevertheless, the biological processes that may favor T. cruzi persistence in the CNS cells remain unclear. Recently, we showed that in chronically infected $\mathrm{C} 3 \mathrm{H} / \mathrm{He}$ mice, most $T$. cruzi-bearing astrocytes are located near interferon gamma $(\mathrm{IFN} \gamma)^{+}$ $\mathrm{Iba}^{+}$microglial cells, in the absence of neuroinflammation [29]. The susceptibility of mouse primary astrocyte cultures to T. cruzi infection is increased by IFN $\gamma$, and the anti-TNF antibody infliximab abolished this IFN $\gamma$ induced effect. Therefore, IFN $\gamma$-stimulated infected astrocytes are potential sources of TNF, which may facilitate astrocyte infection [29]. In the present study, we used primary mouse astrocyte cultures and the human U-87 MG lineage to investigate whether T. cruzi infection triggers TNF production and to explore the biological effects of TNF on parasite/astrocyte interaction regarding the $T$. cruzi cycle (invasion by trypomastigotes, growth of intracellular forms, and egression of trypomastigotes) and cytokine profile. Furthermore, we treated $T$. cruzi-infected mice with anti-TNF antibody to investigate whether TNF indeed affects CNS parasitism.

\section{Methods}

\section{Primary mouse astrocyte cultures}

For in vitro experiments, primary mouse astrocyte cell cultures were obtained from the cerebral cortex of 1day-old $\mathrm{C} 57 \mathrm{BL} / 6\left(\mathrm{H}-2^{\mathrm{b}}\right)$ and $\mathrm{C} 3 \mathrm{H} / \mathrm{He}\left(\mathrm{H}-2^{\mathrm{K}}\right)$ mice, as described previously [33]. Briefly, mice were decapitated, and the meninges were removed. Cortices were then isolated and minced, and a single-cell suspension was obtained by mechanical dissociation. The cells from each brain were seeded into a $25-\mathrm{cm}^{2}$ culture flask pre-coated with poly-ornithine $(0.1 \mathrm{mg} / \mathrm{mL}$; SigmaAldrich, St. Louis, MO, USA) and maintained in DMEM/F-12 medium (Gibco, Gaithersburg, MD, USA) containing $10 \%$ fetal bovine serum (FBS; Gibco, Gaithersburg, MD, USA) at $37{ }^{\circ} \mathrm{C}$ in a $95 \%$ humid atmosphere with $5 \% \mathrm{CO}_{2}$. Microglia and other nonadherent cells were removed by gently shaking the culture flasks. Astrocytes from 7 to 10 days of culture were detached with $0.25 \%$ trypsin $+0.02 \%$ EDTA in phosphate-buffered saline (PBS), $\mathrm{pH} 7.2-7.4$, and plated at a density of $10^{5}$ cells per $13-\mathrm{mm}$-diameter polyornithine-coated coverslip in 24-well plates (NUNC, Roskilde, Denmark). Cells were cultured for $24 \mathrm{~h}$ to allow adhesion to coverslips. Details of each experiment are provided in the figure legends. 


\section{Characteristics of primary mouse astrocyte cultures}

The cell composition of primary astrocyte cultures was determined by indirect immunofluorescence using purified mouse anti-glial fibrillary acidic protein (GFAP) (Invitrogen, Carlsbad, CA, USA) and FITCconjugated anti-mouse immunoglobulin secondary antibody (Dako, Carpinteria, CA, USA). Microglia were revealed by surface $\mathrm{CD} 11 \mathrm{~b}$ expression using PECy7-conjugated anti-mouse CD11b monoclonal antibody (eBioscience, San Diego, CA, USA). After cultivation, cells that adhered to coverslips were washed with warm PBS and fixed with methanol. To block nonspecific binding, the cells were incubated for 30 min with normal goat serum diluted $1: 50$ in $0.1 \%$ sodium azide/PBS and then stained for GFAP and CD11b. Negative controls were performed by omitting the primary antibodies. RAW 264.7 mouse macrophage cells (TIB-71 ${ }^{\mathrm{m}}$, ATCC $^{\circ}$, Manassas, VA, USA) cultured in parallel served as a positive control for CD11b expression [29]. The coverslips were mounted onto slides with Prolong Gold Antifade reagent containing the fluorescent nuclear dye DAPI (Life Technologies, Carlsbad, CA, USA), which stains cell nuclei. The samples were then examined on a fluorescence microscope coupled to a digital camera DFC300FX (Leica, Wetzlar, Germany). The acquired images were analyzed using the IM50 Image Manager software (Leica, Wetzlar, Germany).

\section{L-929 fibroblast culture and TNF treatment}

The fibroblast cell line L-929 (CCL- $1^{\mathrm{Tx}}, \mathrm{ATCC}^{\circ}$, Manassas, VA, USA), originated from a $\mathrm{C} 3 \mathrm{H} / \mathrm{An}$ mouse, was kindly provided by Dr. Maria de Nazaré Correia Soeiro (Laboratory of Cellular Biology, IOC, Fiocruz). Cells were cultivated in RPMI medium supplemented with $10 \%$ FBS and $1 \%$ penicillinstreptomycin (Sigma-Aldrich, St. Louis, MO, USA) and maintained at $37{ }^{\circ} \mathrm{C}$ in a $95 \%$ humid atmosphere with $5 \% \mathrm{CO}_{2}$. Cells were detached with $0.25 \%$ trypsin $+0.02 \%$ EDTA in PBS, washed, plated at a density of $5 \times 10^{4}$ cells per 13 -mm-diameter coverslip in 24-well plates (NUNC, Roskilde, Denmark), and incubated for $24 \mathrm{~h}$ to allow adhesion. Cultures were then washed with warm PBS, and the medium was replaced. To assess the effects of TNF in cells other than astrocytes, the fibroblast cultures were either left untreated or were treated with TNF $(1 \mathrm{ng} / \mathrm{mL})$ for $2 \mathrm{~h}$ and then infected as described for astrocytes.

\section{Human astrocyte lineage}

Human U-87 MG glioblastoma cells were purchased from Banco de Células do Rio de Janeiro (BCRJ, Rio de Janeiro, RJ, Brazil). Cells were cultivated in DMEM medium supplemented with $10 \%$ FBS and 1\% penicillinstreptomycin (Sigma-Aldrich, St. Louis, MO, USA) and maintained at $37{ }^{\circ} \mathrm{C}$ in a $95 \%$ humid atmosphere with $5 \% \mathrm{CO}_{2}$. Cell culture dissociation was performed by replacing medium by $0.25 \%$ trypsin $+0.02 \%$ EDTA in PBS. Cells were plated at a density of $10^{5}$ cells per $13-\mathrm{mm}$ diameter poly-ornithine-coated coverslips in 24-well plates (NUNC, Roskilde, Denmark). Details of each experiment are provided in the figure legends.

\section{Parasites for in vitro infection of cells}

Trypomastigote forms of the Colombian Type I $T$. cruzi strain [34] were obtained from cultures of the Vero cell line $\left({\text { CCL } 81^{\mathrm{ma}}}^{\mathrm{At}}\right.$ ATCC $^{\circ}$, Manassas, VA, USA) maintained in $25-\mathrm{cm}^{2}$ cultivation bottles (Falcon, Austin, TX, USA) using RPMI-1640/HEPES (SigmaAldrich, St. Louis, MO, USA). After 5 to 7 days in culture, the trypomastigote-containing supernatants were centrifuged $\left(20 \mathrm{~min}, 1400 \times g\right.$ at $4{ }^{\circ} \mathrm{C}$ ); the parasites concentrated in the pellet were then resuspended, counted in a Neubauer chamber, and added to astrocyte or fibroblast cultures. Depending on the experimental design, we used a multiplicity of infection (MOI) of 1:1 or 10:1 (parasite/cell) and interaction periods of 4 or $24 \mathrm{~h}$.

\section{Treatment of astrocytes with recombinant IFN $\gamma$ and TNF in vitro}

To investigate the effects of IFN $\gamma$ and TNF on the $T$. cruzi infection of astrocytes in vitro, astrocytes were plated at a density of $10^{5}$ cells per 13 -mm-diameter poly-ornithine-coated coverslip in 24-well plates (NUNC, Roskilde, Denmark) and allowed to adhere for $24 \mathrm{~h}$. Cultures were then washed three times with warm PBS to remove non-adherent cells, and fresh culture medium supplemented with FBS was added. Cultures of U-87 MG human astrocytes or murine primary astrocytes were left untreated or were pre-treated with human or murine recombinant IFN $\gamma$ ( $\mathrm{IIFN \gamma}$, $10 \mathrm{ng} / \mathrm{mL}$, eBioscience, San Diego, CA, USA) or TNF (rTNF, 0.1, 0.5, 1, 5, or $10 \mathrm{ng} / \mathrm{mL}$, eBioscience, San Diego, CA, USA) for different time periods depending on the experimental design (Figs. 1, 2, 3, 4, 5, and 6 and Additional file 3: Figure S3, Additional file 4: Figure S4, Additional file 5: Figure S5, Additional file 6: Figure S6, Additional file 7: Figure S7). Infection was performed with trypomastigotes of the Colombian $T$. cruzi strain at the indicated MOI. In a set of experiments, rTNF was added after infection, as shown in the experimental design (Fig. 4). The plates were incubated at $37{ }^{\circ} \mathrm{C}$ with $95 \%$ humidity and $5 \% \mathrm{CO}_{2}$. Coverslips were then washed twice with warm PBS, and the cells were fixed in fresh $4 \%$ paraformaldehyde for $10 \mathrm{~min}$. After three washes with PBS, the cells were stained with Giemsa, and the coverslips were mounted onto slides with Entellan (Merck, Darmstadt, 


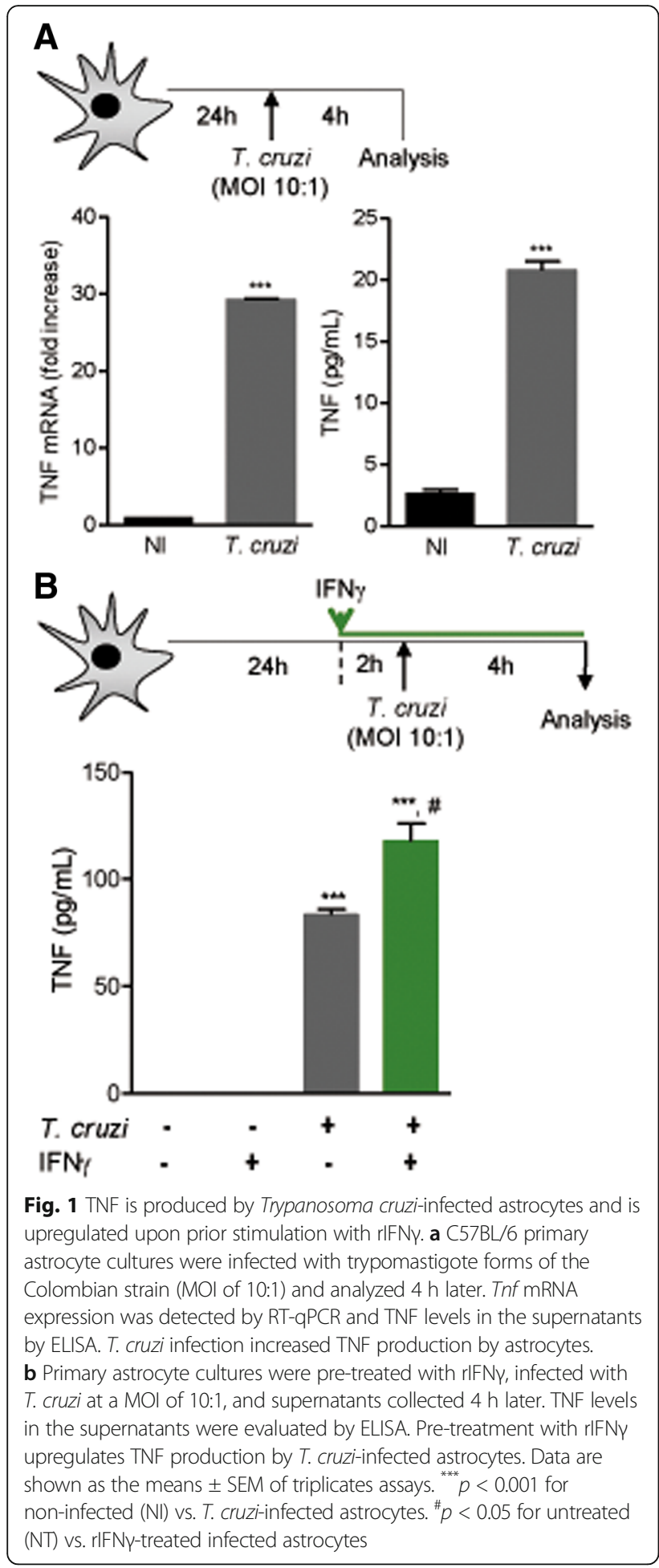

Germany). The numbers of non-infected and T. cruziinfected astrocytes (300 cells/coverslip) and of intracellular amastigote forms per infected cell were counted. Representative images were acquired on a light microscope coupled with a digital camera DS-L3 (Nikon Corporation, Sendai, Japan).

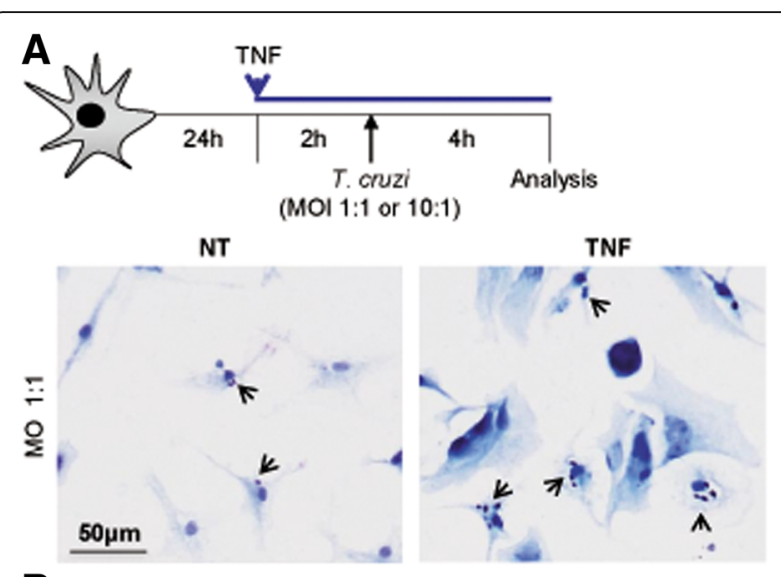

B
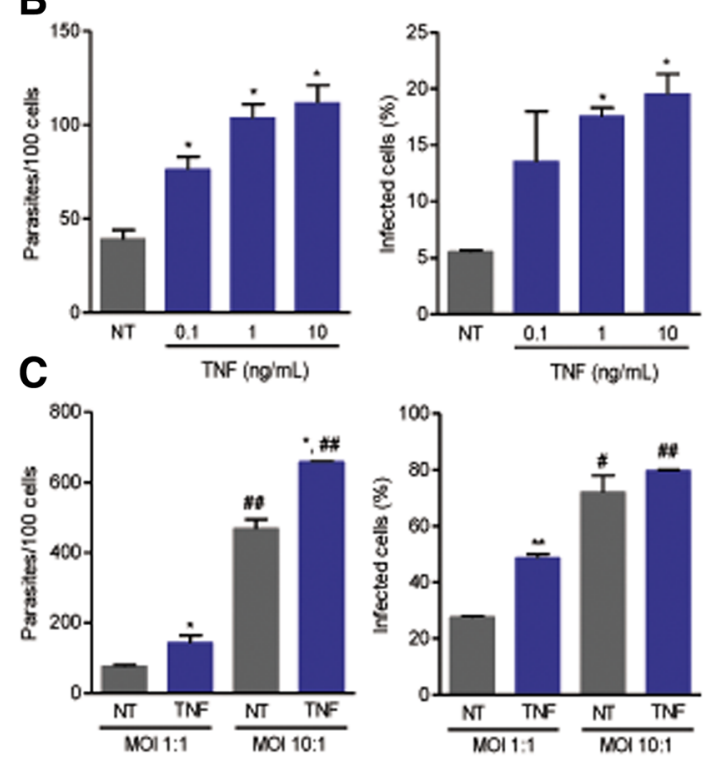

Fig. 2 TNF pre-treatment enhances the infection of astrocyte cultures by Trypanosoma cruzi. a C57BL/6 primary astrocyte cell cultures were pre-treated with rTNF, infected at MOls of 1:1 and 10:1, and analyzed 4 h postinfection. Giemsa staining revealed intracellular forms of T. cruzi (arrows) in untreated (NT) and TNF-treated infected astrocytes. b Astrocyte cultures were pre-treated with $\operatorname{rTNF}(0.1,1,10 \mathrm{ng} / \mathrm{mL}$ final concentrations) and infected with T. cruzi (MOI 1:1, 4 h), and the number of parasites per 100 cells and the percentage of infected cells were analyzed. c Number of parasites per 100 cells and the percentage of infected cells were analyzed after infection at MOls of 1:1 and 10:1 and pre-treatment with $\mathrm{rTNF}$ at $1 \mathrm{ng} / \mathrm{mL}$. Data are presented as the means \pm SEM of triplicates. ${ }^{*} p<0.05$ and ${ }^{* *} p<0.01$ for untreated (NT) vs. rTNF pre-treated astrocytes. ${ }^{\#} p<0.05$ and ${ }^{\# \#} p<0.01 \mathrm{MOl}$ of $1: 1$ vs. MOl of 10:1

\section{Anti-TNF treatment of astrocytes}

To evaluate the role of rIFN $\gamma$-induced TNF in astrocyte infection, cell cultures were treated with the anti-TNF chimeric monoclonal antibody infliximab $(10 \mu \mathrm{g} / \mathrm{mL}$, Remicade, a gift of Schering-Plough, São Antônio, SP, Brazil) $30 \mathrm{~min}$ before the addition of murine or human rIFN $\gamma$, as described in the experimental design (Fig. 3). 


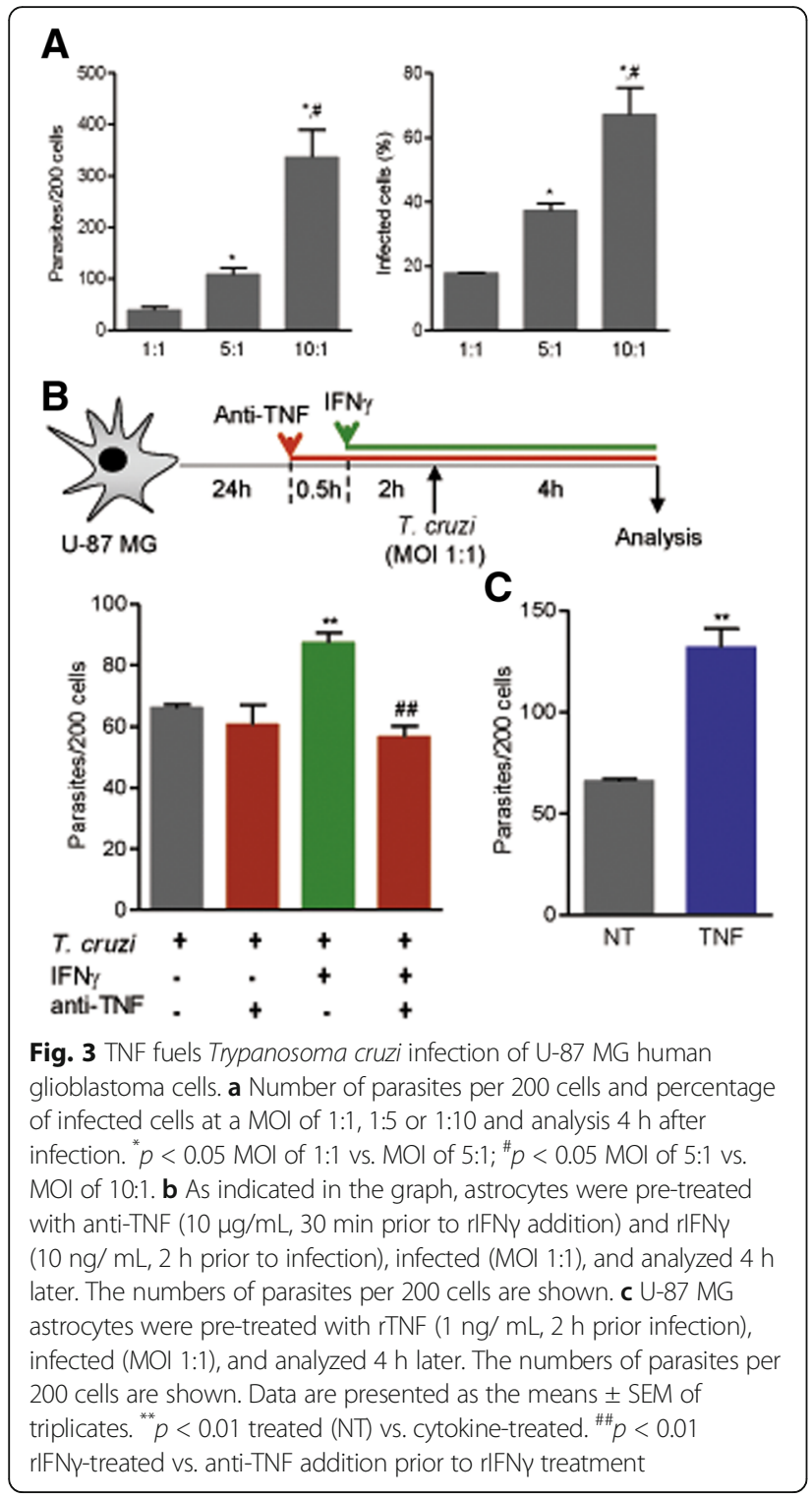

\section{Pentoxifylline treatment of astrocytes}

Pentoxifylline (PTX), a phosphodiesterase inhibitor, has previously been shown to suppress Tnfr1 mRNA expression in the experimental model of hepatic ischemia-reperfusion injury [35] and TNFR1 expression in experimental T. cruzi infection [36]. To explore the effect of PTX on astrocytes, solutions at a final concentration of $30 \mu \mathrm{g} / \mathrm{mL}$ or $100 \mu \mathrm{g} / \mathrm{mL}$ PTX (Trental, Sanofi, São Paulo, SP, Brazil) were added to astrocytes $30 \mathrm{~min}$ prior to rTNF treatment, as described in the experimental design (Fig. 6).

\section{Astrocyte cell viability}

Astrocyte cell viability was observed by the reduction of MTT (3-(4,5-dimethylthiazol-2-yl)-2,5-diphenyltretrazolium bromide; Sigma-Aldrich, Steinheim, Germany).

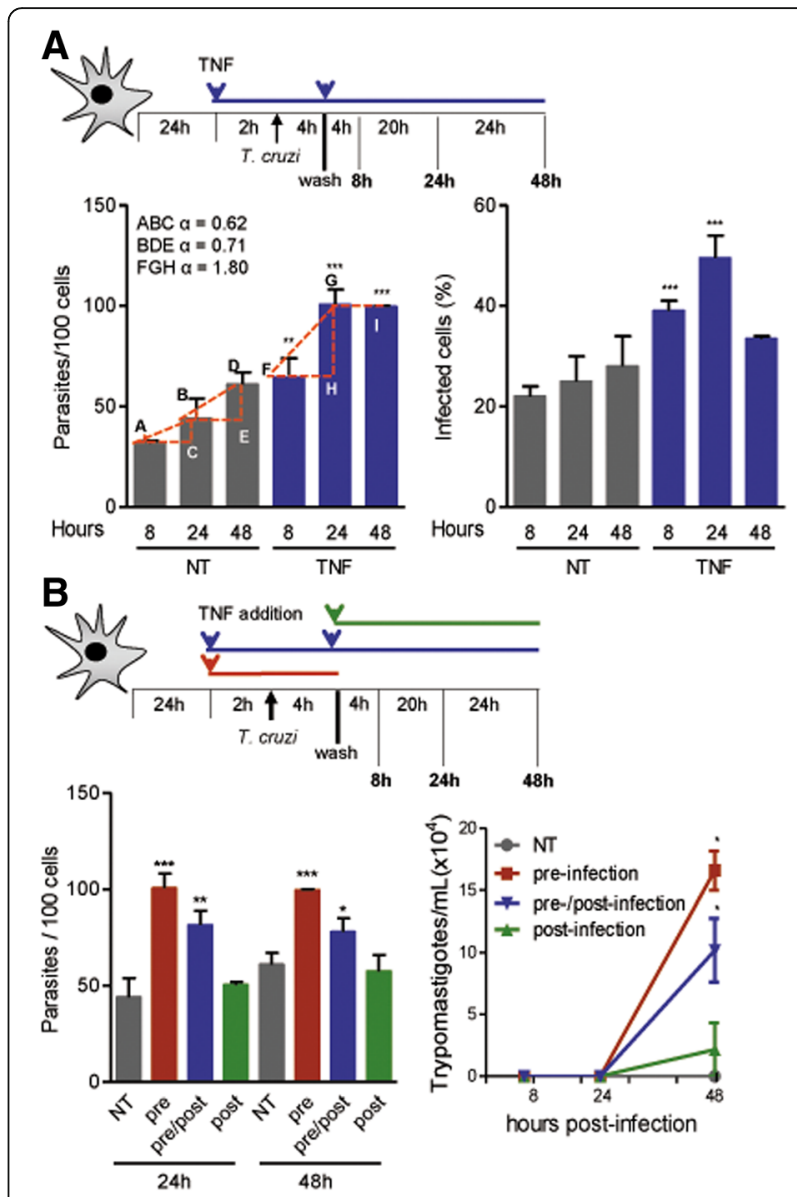

Fig. 4 TNF fuels parasite growth and egression of trypomastigote forms from astrocytes. a C57BL/6 primary astrocyte cultures were treated with rTNF $2 \mathrm{~h}$ before $T$. cruzi infection, and cultures were analyzed after 8, 24, and $48 \mathrm{~h}$ of infection. The numbers of parasites per 100 cells and percentage of infected cells are shown. Estimation of the variation rate of parasite growth A-B-C (0.62), B-D-E (0.71), and F-G-H (1.80). b Astrocytes were treated with $r T N F(1 \mathrm{ng} / \mathrm{mL})$ : prior to infection and removed after (pre), prior to and after infection (pre/post), or only after infection (post). The numbers of intracellular forms of the parasite per 100 astrocytes and trypomastigote forms present in the supernatants are shown. Data are presented as the means \pm SEM of triplicates. ${ }^{*} p<0.05 ;{ }^{* *} p<0.01 ;{ }^{* * *} p<0.001$ untreated (NT) controls vs. rTNF treatment under the distinct experimental conditions

Viable cells convert the yellow, water-soluble tetrazolium salt to insoluble purple formazan. After $5 \mathrm{~min}$, formazan was solubilized with dimethyl sulfoxide (DMSO; SigmaAldrich, St. Louis, MO, USA), and the optical density was evaluated at $490 \mathrm{~nm}$ using a microplate reader (Asys Expert Plus, Biochrom, Cambridge, UK).

\section{Cytokine quantification}

TNF concentrations in cell culture supernatants and mouse sera were evaluated using an ELISA kit for the detection of mouse TNF (R\&D System, Minneapolis, MN, USA) according to the manufacturer's protocol, and the colorimetric reaction was assessed on an ELISA 


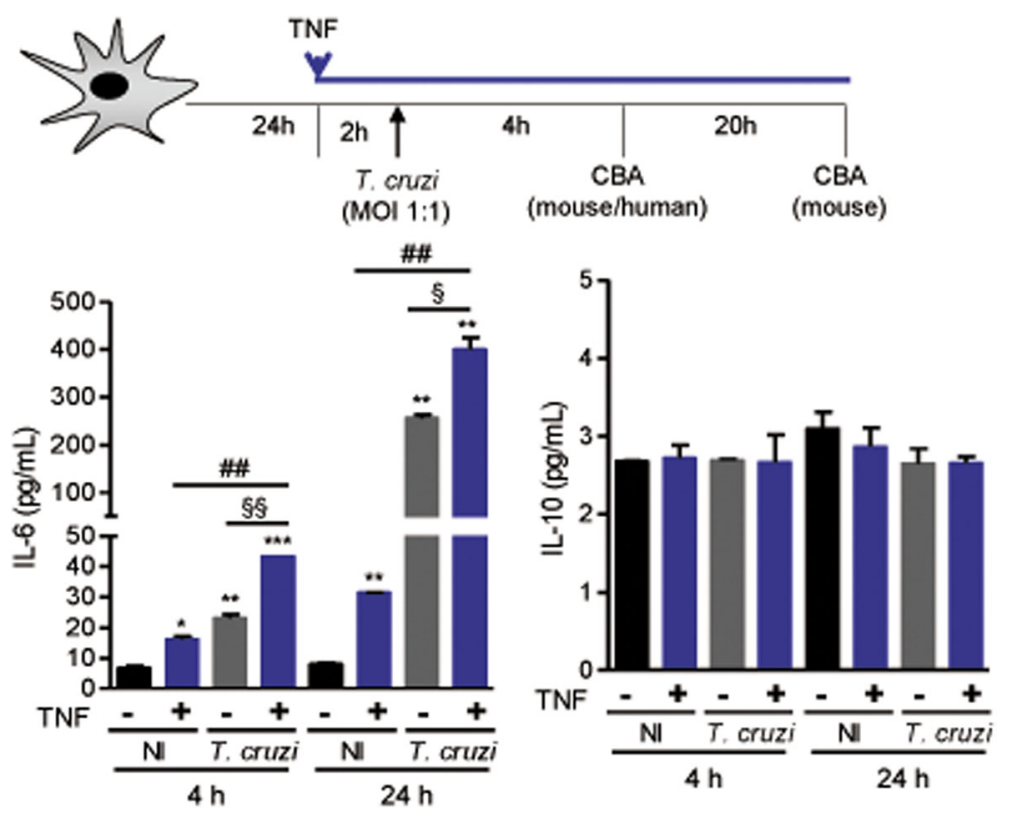

Fig. 5 Trypanosoma cruzi infection-induced IL-6 production by astrocytes is exacerbated by pre-treatment with TNF. C57BL/6 primary astrocyte cultures were pre-treated with rTNF (1 ng/mL) and infected (MOI 1:1), and then the supernatants were collected after 4 and $24 \mathrm{~h}$ of infection and analyzed to detect cytokines by CBA. The concentrations of IL-6 and IL-10 are shown. Data are presented as the means \pm SEM of triplicates. ${ }^{*} p<0.05,{ }^{* *} p<0.01,{ }^{* * *} p<0.001$ untreated (-)/non-infected (NI) vs. other conditions. ${ }^{\# \#} p<0.01$ non-infected (NI) vs. T. cruzi-infected. ${ }^{\S} p<0.05$, $\S^{\S \S} p<0.01$ untreated vs. rTNF pre-treated infected astrocytes

plate reader at $490 \mathrm{~nm}$ (Asys Expert Plus, Biochrom, Cambridge, UK). Cytokines (IL-2, IL-4, IL-6, IL-10, IL$17 \mathrm{~A}$, and TNF) were detected in astrocyte culture supernatants using the commercial cytometric bead array (CBA) Mouse Th1/Th2/Th17 Cytokine Kit (\# 560485, Becton-Dickinson, San Jose, CA, USA) and Human Inflammatory Cytokines Kit (\# 551811, Becton-Dickinson, San Jose, CA, USA) according to the manufacturer's instructions. The fluorescence produced by the beads was measured on a FACSCalibur flow cytometer (BD, Biosciences, San Jose, CA, USA) and analyzed using the kit's FCAP Array software. In the ELISA and CBA tests, standard curves $(1 \mathrm{pg} / \mathrm{mL}$ to $100 \mathrm{ng} / \mathrm{mL})$ were generated in parallel. These methods consistently detected concentrations above $10 \mathrm{pg} / \mathrm{mL}$.

\section{RT-PCR assay to measure in vivo Tnf mRNA expression}

Tnf mRNA expression in brain tissue was assessed and analyzed as previously described [37]. Briefly, RNA was isolated from mouse brains via acid guanidinium thiocyanate-phenol-chloroform extraction: RNA STAT60TM. Total RNA $(0.5 \mu \mathrm{g})$ was reverse transcribed by the addition of $10 \mathrm{U}$ of RNAsin, $15 \rho \mathrm{M}$ oligo DT15 (Promega Corp., Madison, WI, USA), and AMV Reverse Transcriptase (RT) (Gibco, Gaithersburg, MD, USA) in $25-\mu \mathrm{L}$ reactions containing $250 \mathrm{mM}$ dNTPs, $50 \mathrm{mM}$ Tris- $\mathrm{HCl}, \mathrm{pH} 8.3,75 \mathrm{mM} \mathrm{KCl}, 3 \mathrm{mM} \mathrm{MgCl}_{2}$, and
$10 \mathrm{mM}$ DTT. The mixtures were incubated for $5 \mathrm{~min}$ at $95{ }^{\circ} \mathrm{C}, 5 \mathrm{~min}$ on ice, and $5 \mathrm{~min}$ at $25^{\circ} \mathrm{C}$. At this step, $100 \mathrm{U}$ of RT was added to each sample, and the reaction mixture was incubated for $60 \mathrm{~min}$ at $37{ }^{\circ} \mathrm{C}$. The temperature was then elevated to $95{ }^{\circ} \mathrm{C}$ for $5 \mathrm{~min}$, and the tubes were transferred to ice for $5 \mathrm{~min}$. The cDNA products were diluted in $0.2 \mathrm{~mL}$ of sterile distilled water and used at $5 \mu \mathrm{L}$ per reaction for PCR amplifications. The PCR was performed in $25-\mu \mathrm{L}$ reactions with samples diluted in the following buffer: $250 \mathrm{mM}$ dNTPs, $10 \mathrm{mM}$ Tris- $\mathrm{HCl}, \mathrm{pH} 8.3,50 \mathrm{mM} \mathrm{KCl}, 1.5 \mathrm{mM} \mathrm{MgCl}_{2}$, $10 \mathrm{mM}$ of each primer, and $0.5 \mathrm{U}$ of Taq polymerase (CenBiot, Pelotas, RS, Brazil). After an initial incubation for $3 \mathrm{~min}$ at $95{ }^{\circ} \mathrm{C}$, the cycling conditions were denaturation for $1 \mathrm{~min}$ at $94{ }^{\circ} \mathrm{C}$, annealing for $1 \mathrm{~min}$ at $54{ }^{\circ} \mathrm{C}$, and extension for $2 \mathrm{~min}$ at $72{ }^{\circ} \mathrm{C}$. After the designated cycle numbers for each primer, the program executed a final extension of $7 \mathrm{~min}$ at $72{ }^{\circ} \mathrm{C}$. The PCR products and molecular weight markers were separated on $6 \%$ polyacrylamide gels and stained with silver nitrate. Densitometry was carried out on a CS-9301PC Densitometer (Shimadzu, Tokyo, Japan). The PCRs were standardized using hypoxanthine-guanine phosphoribosyl transferase (HPRT). The same primer sequences and PCR conditions indicated previously were here used for detection of Thf and Hprt mRNA [38]. Fold-increases were determined relative to non-infected controls. 

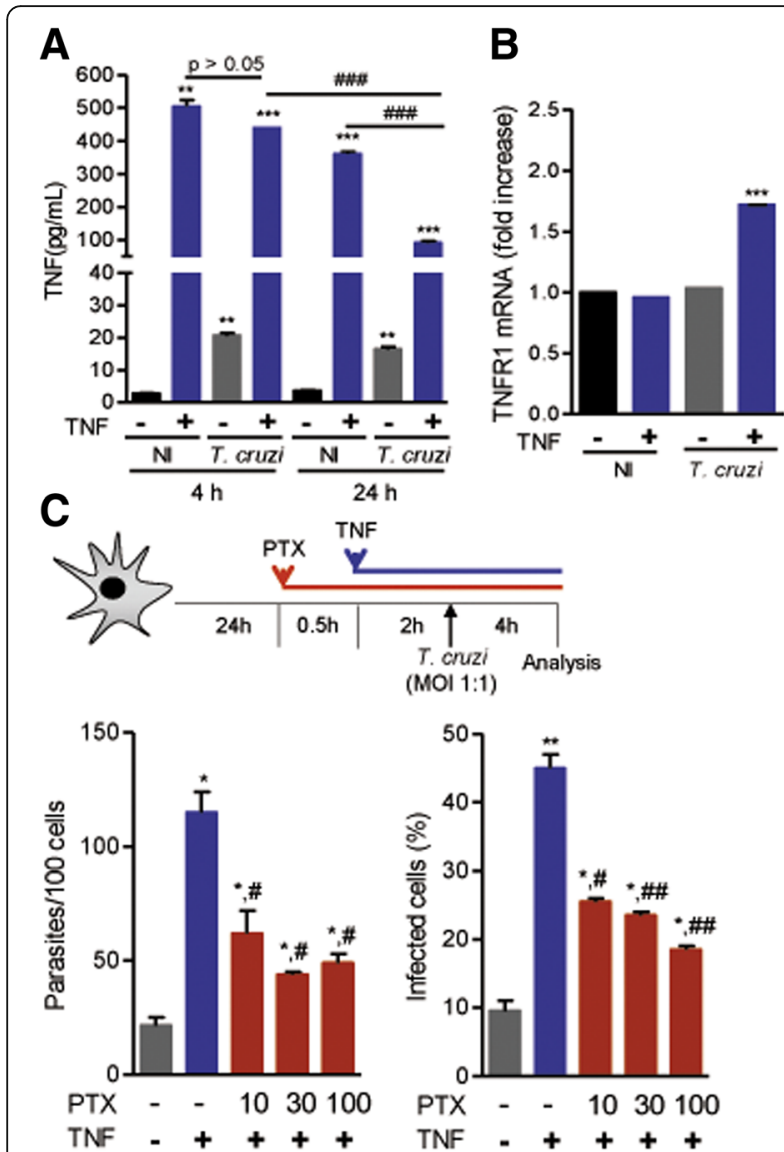

Fig. $\mathbf{6}$ Two signals induce Tnfr 1 mRNA expression, and PTX inhibits rTNF-induced astrocyte invasion by Trypanosoma cruzi. a Astrocytes were pre-treated with rTNF (1 ng/mL) and infected (MOI 1:1), and supernatants were collected after 4 and $24 \mathrm{~h}$ of infection and analyzed for TNF by CBA. b Tnfr1 transcription was detected by RT-qPCR in astrocyte cultures pre-treated with rTNF (1 $\mathrm{ng} / \mathrm{mL})$, infected (MOI 1:1) and analyzed $4 \mathrm{~h}$ postinfection. ${ }^{*} p<0.05,{ }^{* *} p<0.01,{ }^{* * *} p<0.001$ untreated (-)/non-infected (NI) vs. other conditions. ${ }^{\# \# \# ~} p<0.001$ noninfected (NI) vs. T. cruzi-infected. c Experimental scheme showing that C57BL/6 primary astrocyte cultures were pre-treated with PTX (addition 30 min before rTNF; 10, 30, $100 \mu \mathrm{g} / \mathrm{mL}$ ), treated with rTNF (1 ng/mL), and infected with T. cruzi. After $4 \mathrm{~h}$ of infection, the numbers of parasites per 100 cells and the frequency of infected cells were analyzed. Data are presented as the means \pm SEM of triplicates. ${ }^{*} p<0.05$ untreated $(-/-)$ vs. other conditions. ${ }^{*} p<0.05, " \# p<0.01$ rTNF-treated vs. PTX-treated, rTNF-treated infected astrocytes

\section{Real-time RT-qPCR to measure in vitro Tnf and Tnfr 1 mRNA expression}

For real-time quantitative RT-PCR (RT-qPCR), $10^{6}$ astrocytes were cultivated in a 6-well plate (NUNC, Roskilde, Denmark), infected with T. cruzi (MOI 1:1), and cultivated as described above. After $4 \mathrm{~h}$ of culture, astrocytes were washed with warm PBS to remove debris, harvested by gentle scraping with a rubber policeman, and frozen in RNAlater (\# AM7021, Life Technologies, Carlsbad, CA, USA). Total RNA was extracted using TRI-
Reagent (Sigma-Aldrich, St. Louis, MO, USA), after the complete removal of RNAlater. All reverse transcriptase reactions were performed using the SuperScript VILO cDNA Synthesis Kit (Life Technologies, Carlsbad, CA, USA), and real-time RT-qPCR was performed on a RealTime PCR System (Life Technologies, Carlsbad, CA, USA) using TaqMan gene expression kits (Life Technologies, Carlsbad, CA, USA) for Tnf (\# Mm00443258_m1) and Tnfr1 (\#Mm00441883_g1), as well as the endogenous housekeeping control genes glyceraldehyde 3-phosphate dehydrogenase (GAPDH) (\# Mm99999915_g1) and $\beta$ actin (\# Mm00607939_s1), purchased from Life Technologies (Carlsbad, CA, USA). The reactions were performed and analyzed as described previously [28].

\section{Experimental in vivo $T$. cruzi infection}

Five- to 7-week-old female $\mathrm{C} 3 \mathrm{H} / \mathrm{He}\left(\mathrm{H}-2^{\mathrm{K}}\right)$ mice obtained from the animal facilities of the Oswaldo Cruz Foundation (CECAL/Fiocruz, Rio de Janeiro, RJ, Brazil) were housed under specific pathogen-free conditions with a 12-h light/dark cycle and ad libitum access to food and water. Mice were intraperitoneally infected with 100 blood trypomastigotes of the Colombian Type I $T$. cruzi strain obtained by passages through $\mathrm{C} 3 \mathrm{H} / \mathrm{He}$ every 5 weeks. This infection model has been shown to develop self-resolving acute meningoencephalitis $[25,27]$. The experimental groups were composed of six to ten $T$. cruzi-infected mice and three to five non-infected controls per experiment, in three independent experiments (Fig. 7).

\section{In vivo anti-TNF treatment}

At 14 days postinfection (dpi), when the first parasites were detected in peripheral blood, the mice were subcutaneously treated with injection-grade saline (BioManguinhos-Fiocruz, Rio de Janeiro, RJ, Brazil) containing $10 \mu \mathrm{g}$ of anti-TNF antibody (Remicade ${ }^{\circledR}$, Infliximab, Schering-Plough São Antônio, SP, Brazil), at 48-h intervals over 14 days (Fig. 7). Infliximab was previously shown to block TNF activity in vivo in murine models [39] and to decrease serum TNF levels and Tnf mRNA expression in the heart tissue in T. cruziinfected mice [40].

\section{Immunohistochemical staining for parasites}

Groups of non-infected and infected mice, with or without anti-TNF treatment, were sacrificed under anesthesia (100 mg/kg ketamine associated with $5 \mathrm{mg} /$ $\mathrm{kg}$ xylazine chloride, intraperitoneally), at $30 \mathrm{dpi}$. The brains were removed, embedded in tissue-freezing medium (Tissue-Tek, Miles Laboratories, Torrance, CA, USA), and stored in liquid nitrogen. Sagittal brain tissue serial cryostat sections $(8 \mu \mathrm{m}$ thick) were fixed in cold acetone and subjected to immunohistochemical 


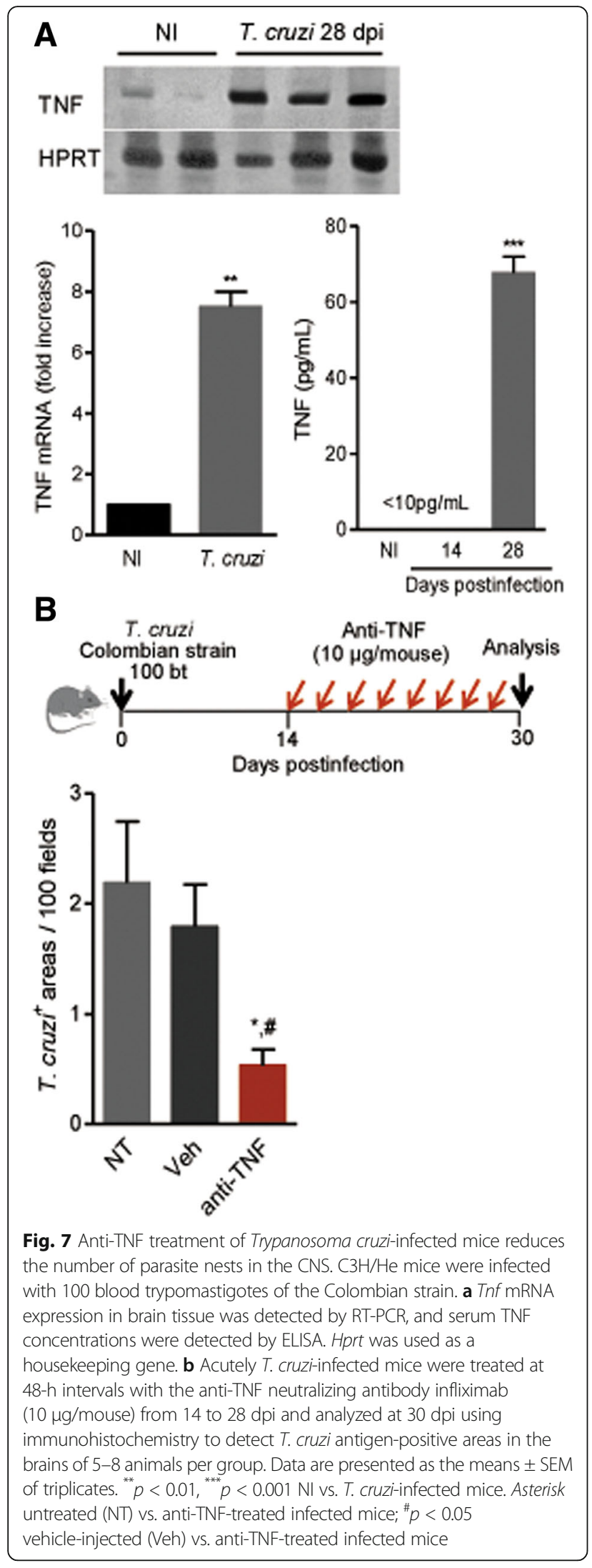

staining. Parasite antigens were revealed by staining with polyclonal rabbit anti-T. cruzi antibody (produced in our laboratory, LBI/IOC-Fiocruz, Rio de Janeiro, RJ, Brazil) and FITC-labeled goat anti-rabbit secondary antibody (Amersham Life Science, Buckinghamshire, UK). Negative-control brain tissue sections were generated by omitting the primary antibody. Ten sections were analyzed for each studied encephalon. Images were acquired on a fluorescence microscope equipped with a digital camera Eclipse CI (Nikon Corporation, Tokyo, Japan) and analyzed with the Nis-Elements BR 4.0 software (Nikon Corporation, Tokyo, Japan). Areas containing parasites were identified and counted. Data are expressed as T. cruzi-positive areas per 100 microscopic fields.

\section{Statistical analysis}

Data are expressed as arithmetic means \pm standard error (SE). For statistical analyses, we used Student's $t$ test to compare two groups. Comparisons between groups were carried out by analysis of variance (ANOVA) followed by Bonferroni post hoc test. All statistical tests were performed with GraphPad Prism 5.0 (La Jolla, CA, USA). Differences were considered statistically significant when $p<0.05$.

\section{Results}

\section{T. cruzi-infected astrocytes produce TNF}

The established primary cell cultures of brain cortex astrocytes were composed mainly of $\mathrm{GFAP}^{+}$cells $(\geq 99 \%)$, while $\mathrm{CD}_{11 \mathrm{~b}}{ }^{+}$cells $(<1 \%)$ were rarely detected (Additional file 1: Figure S1) and were therefore enriched in astrocytes, as recommended for the study of monotypic cell cultures [41, 42]. At $4 \mathrm{~h}$ of $T$. cruzil astrocyte interaction using initial MOIs of $1: 1$ and $10: 1$, nearly 25 and $60 \%$ of astrocytes, respectively, were infected (Additional file 2: Figure S2). At $24 \mathrm{~h}$ of T. cruzi/astrocyte interaction using MOIs of $1: 1$ and 10:1, more than 70 and $90 \%$ of astrocytes, respectively, harbored amastigote-like forms in the cytoplasm (Additional file 2: Figure S2). Therefore, these monotypic astrocyte cultures obtained from C57BL/6 mice are highly susceptible to $T$. cruzi infection. Next, we investigated whether $T$. cruzi-infected astrocytes express Tnf mRNA and produce this cytokine. Compared with non-infected astrocytes, increased Tnf mRNA expression $(p<0.001)$ and TNF levels $(p<0.001)$ were detected after $4 \mathrm{~h}$ of $T$. cruzi/astrocyte interaction (Fig. 1a). Moreover, compared with non-infected astrocytes $(p<0.001)$ and untreated T. cruzi-infected astrocytes $(p<0.05)$, TNF production was upregulated in rIFN $\gamma$-treated T. cruzi-infected astrocytes (Fig. 1b). 


\section{Pre-treatment of astrocytes with TNF stimulates infection by $T$. cruzi}

To examine the influence of TNF on $T$. cruzi/astrocyte interaction and parasite growth inside astrocytes, primary astrocyte cultures were pre-treated with rTNF and then infected with trypomastigote forms at MOIs of $1: 1$ and 10:1 (Fig. 2a). After $4 \mathrm{~h}$ of interaction (MOI of $1: 1$ ), the parasite load inside the invaded astrocyte and frequency of infected astrocytes were higher when rTNF was added prior to $T$. cruzi infection $(p<0.05)$ than for untreated astrocytes (Fig. 2b). As similar results were observed when 1 or $10 \mathrm{ng} / \mathrm{mL}$ was used, we adopted a final concentration of $1 \mathrm{ng} / \mathrm{mL}$ for subsequent experiments. Notably, the addition of rTNF ( 0.5 to $10 \mathrm{ng} / \mathrm{mL})$ to primary astrocyte cell cultures had no cytotoxic effects on astrocytes (Additional file 3: Figure S3). Compared with the corresponding untreated controls, pre-exposing astrocytes to rTNF increased cell invasion by $T$. cruzi when the initial MOI was 1:1 $(p<0.05)$ or 10:1 $(p<0.05)$ (Fig. 2c). TNF addition prior to infection also increased the frequency of infected astrocytes when the initial MOI was 1:1 $(p<0.01)$, but had no impact when the MOI was 10:1 $(p=0.339)$, when a high frequency $(75-80 \%)$ of infected cells was already observed in untreated astrocytes (Fig. 2c).

To test whether the ability of TNF to promote $T$. cruzi/astrocyte interaction was a common biological process in other cell types, L-929 mouse fibroblasts were pre-treated with TNF and then infected with $T$. cruzi (Additional file 4: Figure S4A). Pre-exposing fibroblasts to TNF had no effect on the T. cruzi/fibroblast interaction $(p>0.05)$, regardless of the MOI $(1: 1$ or $10: 1$ ) and time ( 4 or $24 \mathrm{~h}$ ) of interaction (Additional file 4: Figure S4B-C).

\section{Infection of human astrocytes with $T$. cruzi is also fueled by TNF}

To investigate the effect of TNF on the infection of human astrocytes by $T$. cruzi, we used the U-87MG astrocyte cell lineage. After $4 \mathrm{~h}$ of infection, the numbers of parasites/astrocyte $(p<0.05)$ and frequencies of T. cruzi-infected astrocytes $(p<0.05)$ were dependent on the initial MOI (Fig. 3a). Treating U-87MG astrocytes with rIFN $\gamma$ prior to $T$. cruzi infection increased $(p<0.01)$ the number of amastigote-like forms inside astrocytes (Fig. 3b). Furthermore, the ability of rIFNy to fuel astrocyte infection was prevented $(p<0.01)$ by the addition of the anti-TNF antibody infliximab prior to $\mathrm{rIFN} \gamma$ treatment (Fig. 3b). Conversely, the addition of human rTNF prior to infection increased $(p<0.01)$ the mean number of parasites inside U-87MG astrocytes compared with that of untreated astrocytes (Fig. 3c).

\section{TNF increases parasite growth inside astrocytes}

To analyze the effect of TNF on T. cruzi growth inside astrocytes, we performed a kinetic study. Astrocytes from C57BL/6 mice were seeded for $24 \mathrm{~h}$ and then either left untreated or were treated with rTNF, submitted to infection, washed to remove non-internalized trypomastigotes, and cultured for 8, 24, and 48 h (Fig. 4a). At these time intervals, compared with the corresponding untreated controls, an increased number of intracellular forms was detected in rTNF-treated astrocytes $(p<0.01$, $8 \mathrm{~h} ; p<0.001,24$ and $48 \mathrm{~h}$ ). Comparing the mean number of parasites inside astrocytes at 8 and $24 \mathrm{~h}$ of interaction revealed that the proliferation ratio of amastigote forms inside rTNF-treated astrocytes $(\alpha=1.8)$ was almost threefold higher than that inside untreated astrocytes $(\alpha=0.62)$. At 8 and $24 \mathrm{~h}$ of infection, compared with their respective untreated control astrocytes, the frequencies of infected astrocytes were also augmented in rTNF-treated astrocytes $(p<0.001)$. At $48 \mathrm{~h}$ of infection, the frequency of infected astrocytes was drastically reduced when cells were pre-treated with rTNF, suggesting the rupture of astrocytes harboring a high number of parasites (Fig. 4a).

\section{TNF favors parasite egression from astrocytes}

Initially, we tested whether the effect of rTNF on astrocyte infection by $T$. cruzi depends on the timing of cytokine exposure: prior to infection, prior to and sustained during infection, or after infection (Fig. 4b). At 24 and $48 \mathrm{~h}$ postinfection, the mean number of parasites per astrocyte was increased when rTNF was added to target cells prior to and removed after infection compared with that in the corresponding untreated control astrocytes $(p<0.001$, for both 24 and $48 \mathrm{~h})$. At these time-points, higher parasite loads were also detected when rTNF was added prior to and sustained after infection than for the corresponding controls ( $p=0.01,24 \mathrm{~h} ; p<0.05,48 \mathrm{~h}$ ). However, when rTNF was added after $T$. cruzi infection, no effect ( $p=0.586,24 \mathrm{~h} ; p=0.206,48 \mathrm{~h}$ ) on the parasite load was seen compared with the corresponding untreated astrocytes (Fig. 4b). Similarly, we evaluated the frequency of infected cells stratified into classes based on the number of parasites within their cytoplasm. At $24 \mathrm{~h}$ of interaction, compared with the corresponding untreated control astrocytes, the addition of rTNF in the three experimental conditions enhanced $(p<0.05)$ the frequency of astrocytes harboring a higher number of amastigote-like forms. At $48 \mathrm{~h}$ of interaction, compared with the corresponding untreated control astrocytes, both experimental conditions using rTNF prior to infection enhanced the frequency of astrocytes harboring $>6$ amastigotes/astrocyte $(p<0.05)$; however, no change was detected when rTNF was added after infection (Additional file 5: Figure S5). Together, these data 
suggest that in addition to fueling parasite/astrocyte interaction, pre-treating astrocytes with rTNF prior to $T$. cruzi infection may also favor parasite egression. Therefore, to test this idea, astrocytes were submitted to rTNF treatment at different time-points as described above, and the number of trypomastigotes in the supernatant was counted at 8,24 , and $48 \mathrm{~h}$ of infection. Trypomastigotes emerged from untreated astrocytes after 96 or $120 \mathrm{~h}$ (data not shown). At 8 and $24 \mathrm{~h}$ of infection, no trypomastigotes were detected in any of the cell culture supernatants. At $48 \mathrm{~h}$ of infection, compared with the corresponding untreated control astrocytes, a significant increase in the egression of trypomastigote forms was detected when rTNF was added prior to and removed after infection or was added prior to and sustained after infection $(p<0.05$, for both conditions), but no significant effect $(p=0.431)$ was detected when rTNF was added after infection (Fig. 4b).

\section{rTNF amplifies the pro-inflammatory profile of astrocytes exposed to $T$. cruzi infection}

The effect of TNF on cytokine production in the presence of $T$. cruzi infection was analyzed using CBA assays to detect mouse and human Th1/Th2/Th17 cytokines (Fig. 5; Additional file 6: Figure S6). At 4 and $24 \mathrm{~h}$, increased concentrations of IL- 6 were detected in the supernatants of $T$. cruzi-infected mouse astrocyte cultures $(p<0.01$, for both time-points) compared with noninfected astrocytes. Treating non-infected astrocytes with rTNF also enhanced ( $p<0.05,4 \mathrm{~h} ; p<0.01,24 \mathrm{~h})$ IL-6 concentrations in the culture supernatants (Fig. 5). Furthermore, at both time-points, rTNF exposure prior to T. cruzi infection of mouse astrocytes increased IL-6 production compared with untreated and non-infected $(p<0.001,4 \mathrm{~h} ; p<0.01,24 \mathrm{~h})$, rTNF-treated noninfected $(p<0.01$, both time-points), and T. cruzi-infected astrocytes $(p<0.01,4 \mathrm{~h} ; p<0.05,24 \mathrm{~h})$, although a synergistic effect of rTNF and T. cruzi infection was not detected. By contrast, under all experimental conditions, the regulatory cytokine IL-10 was barely detected and was comparable to non-infected controls (Fig. 5). An inflammatory milieu with increased concentrations of IL- 6 was also detected in the supernatants of $T$. cruziinfected $(p<0.05)$, rTNF-treated $(p<0.05)$, or rTNFprimed and infected $(p=0.063)$ human U-87MG astrocytes. Under these conditions, IL-10 was not detected (Additional file 6: Figure S6). At 4 and $24 \mathrm{~h}, T$. cruzi-infected mouse astrocytes released higher levels of TNF than non-infected astrocytes $(p<0.05$, both timepoints). Interestingly, a significant decay $(p<0.001)$ in TNF concentrations in the supernatants of rTNF-treated T. cruzi-infected astrocytes compared with rTNF-treated non-infected astrocytes was observed at $24 \mathrm{~h}$, suggesting consumption of the added TNF (Fig. 6a).

\section{Two signals promptly induce Tnfr 1 expression}

The apparent consumption of the added rTNF by $T$. cruzi-infected astrocytes (Fig. 6a) led us to wonder whether TNF receptors were induced by rTNF or $T$. cruzi infection. We therefore analyzed Tnfr1 mRNA expression by RT-qPCR. At $4 \mathrm{~h}$ after infection, similar Tnfr 1 transcript levels were detected in untreated or rTNF-treated non-infected astrocytes and in T. cruzi-infected astrocytes. Importantly, T. cruzi infection of rTNF-primed astrocytes promptly increased $(p<0.001)$ Tnfr 1 mRNA expression (Fig. 6b), supporting the hypothesis that these two signals are required to upregulate TNFR1 expression on astrocytes.

\section{Pentoxifylline inhibits TNF-fueled astrocyte infection by $T$. cruzi}

PTX, a methylxanthine derivative and nonspecific phosphodiesterase inhibitor, diminishes TNFR1 expression in non-glial cells $[35,36]$. Thus, we examined whether PTX would interfere with TNF-fueled T. cruzil astrocyte interaction. To test this idea, astrocytes were sequentially pre-treated with PTX, treated with rTNF, and submitted to T. cruzi interaction (Fig. 6c). The rTNF-induced increase in the number of amastigote-like forms/astrocyte was partially abrogated by PTX addition at 10,30 , or $100 \mu \mathrm{g} / \mathrm{mL}(p<0.05$, for all three concentrations). PTX treatment also partially inhibited $(p<0.05$, $10 \mu \mathrm{g} / \mathrm{mL} ; p<0.01,30$ and $100 \mu \mathrm{g} / \mathrm{mL}$ ) the rTNF-fueled augmentation of the frequency of $T$. cruzi-infected astrocytes (Fig. 6c).

\section{In vivo $T$. cruzi infection of $\mathrm{C} 3 \mathrm{H} / \mathrm{He}$ mice enhances TNF expression in the CNS and systemically}

Acutely $T$. cruzi-infected $\mathrm{C} 3 \mathrm{H} / \mathrm{He}$ mice present meningoencephalitis in the presence of brain parasitism $[25,29]$. Hence, we examined the impact of $T$. cruzi infection on TNF expression in the CNS and systemically in acutely (14 and $28 \mathrm{dpi}$ ) Colombian-infected $\mathrm{C} 3 \mathrm{H} / \mathrm{He}$ mice. At $28 \mathrm{dpi}$, increased brain Tnf mRNA expression $(p<0.01)$ and high serum TNF concentrations $(p<0.001)$ were detected in infected mice compared with those in non-infected controls (Fig. 7a).

\section{Anti-TNF diminishes parasite load in the CNS of acutely $T$. cruzi-infected $\mathrm{C} 3 \mathrm{H} / \mathrm{He}$ mice}

Although not detected at 7 and 14 dpi (data not shown), at $30 \mathrm{dpi}, T$. cruzi parasite nests were observed in the CNS of Colombian-infected $\mathrm{C} 3 \mathrm{H} / \mathrm{He}$ mice (Fig. 7b). Initially, we found that the ability of rTNF to fuel the infection of primary C57BL/6 astrocyte cultures by $T$. cruzi was conserved in astrocytes from the $\mathrm{C} 3 \mathrm{H} / \mathrm{He}$ mouse lineage (Additional file 7: Figure S7). Next, we tested whether TNF fuels in vivo T. cruzi parasitism in the CNS using infected $\mathrm{C} 3 \mathrm{H} / \mathrm{He}$ mice treated at $48-\mathrm{h}$ 
intervals with the anti-TNF antibody infliximab from 14 to $28 \mathrm{dpi}$ and analyzed at $30 \mathrm{dpi}$. Notably, the number of T. cruzi-positive areas in the brain was significantly reduced in anti-TNF-treated mice compared with untreated or vehicle-injected ( $p<0.05$, for both conditions) acutely infected $\mathrm{C} 3 \mathrm{H} / \mathrm{He}$ mice (Fig. 7b).

\section{Discussion}

In the present study, we show that (i) TNF is produced by $T$. cruzi-infected astrocytes and is upregulated by IFNY stimulation prior to infection; (ii) TNF priming fuels astrocyte infection, accelerates amastigote multiplication and trypomastigote egression; (iii) TNF-primed infected astrocytes create a TNF- and IL-6-enriched inflammatory milieu; and (iv) TNF/TNFR1 signaling may fuel parasite infection. Furthermore, treating infected mice with TNF antibody revealed that TNF facilitates $T$. cruzi parasitism in the CNS, reinforcing the biological relevance of our in vitro findings.

We first showed that primary astrocyte cultures from C57BL/6 mice and the human U-87 MG lineage are targets of $T$. cruzi infection, corroborating previous data using astrocytes from $\mathrm{C} 3 \mathrm{H} / \mathrm{He}$ mice [29] and the human CRl-1718 astrocyte lineage [43]. Therefore, susceptibility of astrocytes to T. cruzi infection in vitro is preserved in different mouse genetic backgrounds and among species. In Chagas disease patients and experimental models, astrocytes are preferred targets for $T$. cruzi invasion and proliferation in the CNS, regardless of the host species and parasite strain [21, 26, 29, 44]. Thus, the experimental models proposed here are appropriate to test our hypotheses.

Mouse and human astrocytes respond to T. cruzi infection by producing TNF, which is upregulated by rIFN stimulation prior to T. cruzi infection. In experimental African trypanosomiasis (sleeping sickness), Tnf transcripts were detected concomitant with astrocyte activation, indicating that these glial cells may be sources of TNF [45]. Additionally, in a cerebral malaria model, Tnf mRNA was detected by in situ PCR in astrocytes [46], indicating that astrocytes are activated and respond by upregulating TNF production in different parasitic diseases. However, the biological consequences of TNF production by astrocytes under these conditions were not entirely explored. In Chagas disease patients, high TNF plasma levels are associated with disease severity $[17,18,47]$. In chronically infected mice, serum TNF concentrations are associated with overall disease severity, including parasitemia and parasite load in the heart tissue $[19,48]$. Therefore, we assessed the role of TNF in the $T$. cruzi/astrocyte interaction. Interestingly, the anti-TNF blocking antibody infliximab hampered the IFN $\gamma$-induced increase in human astrocyte susceptibility to T. cruzi infection, supporting the role of TNF in this process. Indeed, pre-treating murine and human astrocytes with TNF fuels $T$. cruzi invasion, revealing a conserved biological activity of TNF. However, this biological process is not common to all cell types because pre-treating fibroblasts with TNF did not facilitate T. cruzi infection.

The ability of TNF to fuel astrocyte invasion by $T$. cruzi depends on when astrocytes experience this cytokine. In fact, this outcome was restricted to treatment prior to infection, but not when TNF was added after infection. Interestingly, treating T. cruzi-infected astrocytes with TNF had no effect on parasite growth control. Previously, TNF has been shown to facilitate the invasion of non-professional phagocytic epithelial cell lines by $T$. cruzi via NF-kB activation [49]. Interestingly, in vivo TNF therapy aggravates acute infection [50]. Conversely, TNF improves the control of amastigote multiplication in mouse peritoneal macrophages $[50,51]$. Regarding the role of cytokines in T. cruzi infection, transforming growth factor $\beta$ has been shown to enhance $T$. cruzi invasion and replication in epithelial cells [52] and primary cardiomyocyte cultures [53]. However, the influence of cytokines on the ability of $T$. cruzi to complete the cycle allowing egression of trypomastigote forms has not been previously studied. Our data showed that TNF increases intracellular parasite growth and accelerates trypomastigote egression when added to astrocytes prior to infection but not after infection. Therefore, depending on the timing of exposure, TNF favors the complete $T$. cruzi cycle in the primary CNS-resident cell. The possibility that TNF acts on the expression of cell surface molecules or other inflammatory mediators that drive the invasion of and egression from astrocytes by $T$. cruzi cannot be excluded. Indeed, we recently showed that nitric oxide may also contribute to IFN $\gamma$-driven astrocyte invasion by $T$. cruzi [29].

Astrocytes infected by Toxoplasma gondii create a regulatory milieu with high IL-10 concentrations that downmodulate the inflammatory profile of IFNyactivated microglia and impair neuronal death [33]. By contrast, high concentrations of TNF and IL-6, but not of the regulatory cytokine IL-10, were produced by astrocytes after $T$. cruzi infection and were upregulated by TNF stimulation. Therefore, in the presence of $T$. cruzi infection, astrocytes likely generate an inflammatory milieu in the CNS. Nevertheless, whether the cytokines released by CNS-resident cells in response to T. cruzi infection are beneficial or detrimental remains unclear. In vivo, the production of pro-inflammatory cytokines such as IL-6 and TNF by CNS-resident cells may help clear debris, repair and regenerate nervous tissue. However, prolonged exposure to high levels of these cytokines may worsen or accelerate tissue 
dysfunction and degenerative processes [12]. IL-6 is a cytokine with pleiotropic effects [54]. In experimental autoimmune encephalomyelitis, astrocyte-derived IL-6 present in neuroinflammatory lesions has been implicated in motor disability and disease progression [55]. In chagasic infection, IL-6 produced in situ may synergize with other cytokines to play a detrimental role in the CNS, a question that should be pursued. Interestingly, $T$. cruzi-infected mice present systemically elevated levels of IFN $\gamma$ and TNF [19, 28, 40, 47] and IFN $\gamma^{+} \mathrm{Iba}^{-} 1^{+}$glial cells surrounding $\mathrm{GFAP}^{+} T$. cruzibearing astrocytes [29]. In chronic T. cruzi infection, systemic TNF has emerged as a key cytokine in the pathogenesis of cardiomyopathy and the dysregulation of the immune response in the spleen and bone marrow [40]. A collection of data suggest that increased systemic IFN $\gamma$ - and TNF-induced activation of the tryptophan-degrading enzyme indoleamine 2,3-dioxygenase, as well as neuroinflammation, contribute to behavioral abnormalities [56]. In T. cruzi infection, systemically disturbed IFN $\gamma$ and TNF production may create a TNF-enriched environment in the CNS that may fuel parasitism but also create a deleterious circuit, leading to behavioral alterations. In line with this idea, systemic treatment with anti-TNF antibody or with the TNFR1 modulator PTX ameliorated depressive-like behavior in chronically $T$. cruzi-infected mice [28], suggesting that TNF signaling via TNFR1 may play a key role in behavioral alterations in T. cruzi infection.

To shed light on the mechanism by which TNF fuels astrocyte infection by T. cruzi, we analyzed TNFR1 expression on these glial cells. TNF failed to upregulate Tnfr 1 transcription, corroborating previous data [10]. However, increased Tnfr 1 mRNA expression was detected in the presence of both TNF and T. cruzi infection, accompanied by increased consumption of TNF. Thus, astrocytes may facilitate T. cruzi persistence in the CNS by inducing TNF production and, in conjunction, these signals may upregulate TNFR1 expression. Indeed, pre-treating astrocytes with PTX reduced the TNF-induced augmentation of astrocyte invasion by $T$. cruzi. PTX has previously been shown to reduce TNF [57-59] and TNFR1 [35, 36] expression, putatively damping TNF/TNFR1 signaling. Together, these results suggest that T. cruzi infection in astrocytes triggers TNF production, which upregulates TNF and TNFR1 expression, creating a feedback circuit that drives the inflammatory milieu and contributes to parasite persistence in the CNS.

Intense CNS parasitism and inflammation by blood-borne leukocytes are detected in the acute phase of $T$. cruzi infection in $\mathrm{C} 3 \mathrm{H} / \mathrm{He}$ mice $[25,27]$. Here, we detected increased brain Tnf mRNA expression and high serum TNF concentrations in acutely Colombian-infected $\mathrm{C} 3 \mathrm{H} / \mathrm{He}$ mice. Therefore, we tested the idea that in vivo TNF fuels $T$. cruzi parasitism in the CNS. Indeed, anti-TNF antibody treatment reduced the number of $T$. cruzi-positive areas in the brain. In chronically $T$. cruzi-infected mice, anti-TNF antibody treatment downregulated systemic TNF and TNFR1 expression [40] and abrogated depressive-like behavior [28]. Interestingly, recent data have shown that acutely high systemic TNF concentrations upregulate $\operatorname{Tnf}$ transcription in the CNS and produce cognitive dysfunction [60]. Nevertheless, our data suggest that systemic or intrinsically produced TNF may facilitate the entry and housing of parasites into CNS-resident cells in acutely $T$. cruzi-infected mice. High systemic TNF concentrations are also detected in chronically $T$. cruzi-infected mice $[19,40]$. Thus, systemic TNF draining from the CNS parenchyma and TNF produced by CNS-resident astrocytes may self-sustain the intrinsic inflammatory milieu and contribute to parasite persistence in the CNS during chronic infection. Although we cannot distinguish what happens first in vivo, increased TNF fueling parasite invasion of astrocytes or parasitism inducing TNF upregulation by CNS-resident cells, we believe that these processes form a feedback loop, which may contribute to parasite persistence in the CNS. Although not explored in the present work, it is tempting to extrapolate our findings to propose that parasite persistence in an apparently silent way concurs to create a potent glial cell-borne inflammatory milieu, which may trigger behavioral alterations in $T$. cruzi-infected individuals.

\section{Limitations}

In vitro models are reductionist approaches and are therefore limited in their ability to reproduce the complexity of the network of interactions occurring in the CNS. Although our in vivo result showing reduced CNS T. cruzi parasitism after anti-TNF treatment allowed an approximation with in vitro data, supporting a role for TNF in astrocyte invasion by $T$. cruzi, directly translating our findings to the pathophysiology of the CNS commitment in Chagas disease is undoubtedly the crucial limitation of our study.

\section{Conclusions}

The TNF-enriched inflammatory milieu created by $T$. cruzi infection of astrocytes may fuel parasite infection of these glial cells via TNF/TNFR1 signaling, thereby perpetuating the parasite cycle in the CNS. 


\section{Additional files}

Additional File 1: Figure S1. Primary cell cultures of C57BL/6 cerebral cortex are enriched in astrocytes. CNS cells of seven to ten days of primary culture were seeded at a density of $10^{5}$ cells per 13-mm-diameter coverslip and analyzed $24 \mathrm{~h}$ later. $(\mathrm{a}, \mathrm{b}, \mathrm{c})$ Giemsa staining reveals cells resembling astrocytes with thin extensions, delicate branches, recognizable nucleoli and cytoplasm lightly stained. (d, e, f) Simultaneous immunohistochemical staining for GFAP and CD11b was used to determine the cell composition of primary astrocyte cultures. (e) Insert showing RAW 264.7 mouse macrophage lineage used as positive control for CD11b staining. (TIFF $1266 \mathrm{~kb}$ )

Additional File 2: Figure S2. Astrocytes from neonatal C57BL/6 mice are susceptible to in vitro infection by Trypanosoma cruzi. (a) Monotypic astrocyte cell cultures were allowed to interact during 4 or $24 \mathrm{~h}$ with Vero cells-born trypomastigote forms of the Colombian T. cruzi strain, at a $\mathrm{MOl}$ of 1:1 or 10:1. (b-e) Astrocyte infected with T. cruzi at a MOl of 1:1 and analyzed after $4 \mathrm{~h}(\mathrm{~b}, \mathrm{c}, \mathrm{d})$ or $24 \mathrm{~h}$ (e) of interaction. (f) Parasites per 100 cells and frequency of T. cruzi-infected astrocytes after 4 and $24 \mathrm{~h}$ of T. cruzi/astrocyte interaction at a $\mathrm{MOI}$ of 1:1 or 10:1 Data are presented as means \pm SEM of triplicates. ${ }^{*}, p<0.05$ and ${ }^{* *}, p<0.01 \mathrm{MOI} 1: 1 \mathrm{vs.} \mathrm{MOI}$ $10: 1$ in each analyzed interval; ${ }^{*}, p<0.05$ and ${ }^{\# \#}, p<0.014 \mathrm{~h}$ vs. $24 \mathrm{~h}$ of infection in each analyzed MOI. (TIFF 1349 kb)

Additional File 3: Figure S3. Addition of rTNF to astrocyte cultures had no cytotoxic effects on astrocytes. C57BL/6 primary astrocyte cultures were seeded at a density of $10^{5}$ cells per $13-\mathrm{mm}$-diameter coverslip, $24 \mathrm{~h}$ later washed with warm PBS and left untreated (NT), treated with rTNF $(0.5,1,5,10 \mathrm{ng} / \mathrm{mL})$ or toxic agents $(\mathrm{HCl} \mathrm{pH} 4.0$ or DMSO). After $24 \mathrm{~h}$ of exposure, cells were submitted to MTT assay. Data are presented as means \pm SEM of triplicates. ${ }^{* * *}, p<0.001$ untreated (NT) vs. astrocytes submitted to other experimental conditions. (TIFF $881 \mathrm{~kb}$ )

Additional File 4: Figure S4. Pre-treatment of fibroblast with rTNF does not affect infection by Trypanosoma cruzi. (a) Experimental scheme showing that L-929 fibroblasts were pre-treated with TNF $(1 \mathrm{ng} / \mathrm{mL})$ and subsequently infected with trypomastigote forms of the Colombian T. cruzi strain. (b-c) The percentage of infected cells and the number of parasites per cells were analyzed at $4 \mathrm{~h}$ (b) and $24 \mathrm{~h}$ (c) of infection, at a MOI of 1:1 or 10:1. Data are presented as mean \pm SEM of duplicates. (TIFF $1430 \mathrm{~kb}$ )

Additional File 5: Figure S5. Pre-exposing astrocyte cultures to rTNF enhances parasite load in Trypanosoma cruzi-infected astrocytes. C57BL/6 primary astrocyte cultures were seeded, exposed to rTNF and infected as described in Fig. 5a. At 24 and 48 h of infection, the frequencies of infected astrocytes were stratified by classes according to the number of amastigotelike forms harbored in the cytoplasm. Data are presented as means \pm SEM of triplicates. ${ }^{*}, p<0.05,{ }^{* *}, p<0.01$ untreated (NT) vs. rTNF-treated astrocytes. (TIFF $1045 \mathrm{~kb}$ )

Additional File 6: Figure S6. rTNF amplifies the pro-inflammatory profile of human astrocytes exposed to Trypanosoma cruzi infection. Human astrocytes were submitted to treatment with rTNF and left non-infected (NI) or infected by T. cruzi (MOI 1:1). At $4 \mathrm{~h}$ of infection, supernatants were collected and submitted to detection of cytokines by CBA. Data are presented as means \pm SEM of triplicates. ${ }^{*}, p<0.05$, untreated (NT) vs. rTNF-treated astrocytes. (TIFF 1375 kb)

Additional File 7: Figure S7. rTNF effects on Trypanosoma cruzi/astrocyte interaction are conserved in primary astrocyte cultures of $\mathrm{C} 3 \mathrm{H} / \mathrm{He}$ mice. (a) Monotypic primary astrocyte cell cultures of $\mathrm{C} 3 \mathrm{H} / \mathrm{He}$ mice were seeded, left untreated or treated with rTNF and infected with trypomastigote forms of the Colombian T. cruzi strain at a MOl of 1:1 or 10:1. (b) After $4 \mathrm{~h}$ of interaction, the frequencies of infected cells and the number in untreated (NT), rTNF-treated astrocytes are shown. (c) Data show the frequencies of infected astrocytes stratified by classes according to the number of amastigote-like forms harbored in the cytoplasm. Data are presented as means \pm SEM of triplicates. ${ }^{*}, p<0.05,{ }^{* * *}, p<0.001$ untreated (NT) vs. rTNFtreated astrocytes. ${ }^{\#}, p<0.05,{ }^{\# \#}, p<0.01,{ }^{\# \#}, p<0.001 \mathrm{MOI} 1: 1$ vs. MOI 10:1. (TIFF $1337 \mathrm{~kb}$ )

\section{Abbreviations}

CBA: Cytometric bad array; CD: Cluster of differentiation; CEUA: Committee for Animal Ethics; CNS: Central nervous system; DAPI: 4',6-Diamidino-2- phenylindole; DMSO: Dimethyl sulfoxide; DNTP: 2'-Deoxynucleoside 5'triphosphates; DPI: Days postinfection; ELISA: Enzyme-linked immunosorbent assay; FBS: Fetal bovine serum; FITC: Fluorescein isothiocyanate; GFAP: Glial fibrillary acidic protein; HIV: Human immunodeficiency virus;

HPRT: Hypoxanthine-guanine phosphoribosyl transferase; Iba-1: lonized calciumbinding adapter molecule 1; IFN: Interferon; IL: Interleukin; IOC: Instituto Oswaldo Cruz/Oswaldo Cruz Institute; MOI: Multiplicity of infection; MTT: 3-(4,5dimethylthiazol-2-yl)-2,5-diphenyltetrazolium bromide; NF-kB: Nuclear factor kappa B; NI: Non-infected; NT: Not-treated; PCR: Polymerase chain reaction; PTX: Pentoxifylline; rIFN: Recombinant interferon; rTNF: Recombinant tumor necrosis factor; RT-qPCR: Quantitative real-time polymerase chain reaction; Th: T helper cells; TNF: Tumor necrosis factor; TNFR1: Tumor necrosis factor receptor 1; TNFR2: Tumor necrosis factor receptor 2

\section{Acknowledgments}

Program for Technological Development in Tools for Health (PDTIS-Fiocruz) for the use of the real-time PCR (RPT09A) and cytometry platforms. J. Lannes-Vieira, O. C. Moreira, and R. M. Mariante are research fellows of the Brazilian Research Council/CNPq. During the development of this study, J. Lannes-Vieira, A. A. Silva, O. C. Moreira, and I. R. Pereira were research fellows of Fundação Carlos Chagas Filho de Amparo à Pesquisa do Estado do Rio de Janeiro/FAPERJ.

\section{Funding}

This work was supported by grants from Fundação Carlos Chagas Filho de Amparo à Pesquisa do Estado do Rio de Janeiro/FAPERJ (CNE/E-26/202.969/ 2015 BBP; E-26/110.153/2013; E-26/111.709/2013; E-26/102.173/2013) and the Brazilian Research Council/CNPq (474,234/2012-6-Universal; DECIT/MS/CNPq 403979/2012-9; BPP 304474/2015-0; PROEP/IOC/CNPq 400,146/2011).

\section{Availability of data and materials}

The datasets during and/or analyzed during the current study are available from the corresponding author on reasonable request.

\section{Authors' contributions}

Conception of the idea: JLV and AAS; experimental design: JLV, AAS, RRS, RMM, and OCM; performing experiments: AAS, RRS, DG, JBS, RMM, IRP, and OCM; data analysis: AAS, RRS, OCM, and JLV; and writing: AAS and JLV. All authors read and approved the final manuscript.

\section{Ethics approval}

This study was carried out in strict accordance with the recommendations in the Guide for the Care and Use of Laboratory Animals of the Brazilian National Council of Animal Experimentation (http://www.cobea.org.br/) and the Federal Law 11.794 (October 8, 2008). The institutional Committee for Animal Ethics of Fiocruz (CEUA/Fiocruz, Licenses 004/09 and LW10/14) approved all the procedures used in the present study.

\section{Consent for publication}

Not applicable.

\section{Competing interests}

The authors declare they have no competing interests.

\section{Publisher's Note}

Springer Nature remains neutral with regard to jurisdictional claims in published maps and institutional affiliations.

\section{Author details}

'Laboratório de Biologia das Interações, Instituto Oswaldo Cruz - Fiocruz, Av. Brasil 4365, Rio de Janeiro, RJ 21040-360, Brazil. Laboratório Multidisciplinar de Apoio à Pesquisa em Nefrologia e Ciências Médicas, Departamento de Patologia, Faculdade de Medicina, Universidade Federal Fluminense, Rua Marquês do Paraná, 303, Niterói, RJ 24033-900, Brazil. ªboratório de Biologia Estrutural IOC/Fiocruz, Av. Brasil 4365, Rio de Janeiro, RJ 21040-360, Brazil. ${ }^{4}$ Laboratório de Biologia Molecular e Doenças Endêmicas, IOC/Fiocruz, Av. Brasil 4365, Rio de Janeiro, RJ 21040-360, Brazil. 'Laboratório de Doença de Chagas, Escola de Farmácia, Universidade Federal de Ouro Preto, Campus Morro do Cruzeiro s/no, Ouro Preto, MG 35400-000, Brazil. '́Laboratório de Hematologia, Departamento de Patologia, Faculdade de Medicina, Universidade Federal Fluminense, Rua Marquês do Paraná, 303, Niterói, RJ 24033-900, Brazil. 
Received: 16 February 2017 Accepted: 27 August 2017 Published online: 06 September 2017

\section{References}

1. Kimelberg HK. Functions of mature mammalian astrocytes: a current view. Neuroscientist. 2010;16(1):79-106.

2. Aronica E, Ravizza T, Zurolo E, Vezzani A. Astrocyte immune responses in epilepsy. Glia. 2012;60(8):1258-68.

3. Lundgaard I, Osório MJ, Kress BT, Sanggaard S, Nedergaard M. White matter astrocytes in health and disease. Neurosci. 2014;276:161-73.

4. Contreras-Ochoa CO, Lagunas-Martínez A, Belkind-Gerson J, Correa D. Toxoplasma gondii invasion and replication in astrocyte primary cultures and astrocytoma cell lines: systematic review of the literature. Parasitol Res. 2012;110(6):2089-94

5. Rossi D. Astrocyte physiopathology: at the crossroads of intercellular networking, inflammation and cell death. Prog Neurobiol. 2015;130:86-120.

6. Park KM, Bowers WJ. Tumor necrosis factor-alpha mediated signaling in neuronal homeostasis and dysfunction. Cell Signal. 2010;22(7):977-83.

7. Jensen CJ, Massie A, De Keyser J. Immune players in the CNS: the astrocyte. J Neuroimmun Pharmacol. 2013;8(4):824-39.

8. Wang J, Al-Lamki RS, Zhang H, Kirkiles-Smith N, Gaeta ML, Thiru S, Pober JS, Bradley JR. Histamine antagonizes tumor necrosis factor (TNF) signaling by stimulating TNF receptor shedding from the cell surface and Golgi storage pool. J Biol Chem. 2003;278(24):21751-60.

9. Li J, Yin Q, Wu H. Chapter five-structural basis of signal transduction in the TNF receptor superfamily. Adv Immunol. 2013;119:135-53.

10. Dopp JM, Mackenzie-Graham A, Otero GC, Merrill JE. Differential expression, cytokine modulation, and specific functions of type-1 and type-2 tumor necrosis factor receptors in rat glia. J Neuroimmunol. 1997;75(1-2):104-12.

11. Li SJ, Liu W, Wang JL, Zhang Y, Zhao DJ, Wang TJ, Li YY. The role of TNF-a, IL-6, IL-10, and GDNF in neuronal apoptosis in neonatal rat with hypoxicischemic encephalopathy. Eur Rev Med Pharmacol Sci. 2014;18(6):905-9.

12. Becher B, Spath S, Goverman J. Cytokine networks in neuroinflammation. Nat Rev Immunol. 2017;17(1):49-59.

13. Sternberg JM, Rodgers J, Bradley B, Maclean L, Murray M, Kennedy PG. Meningoencephalitic African trypanosomiasis: brain IL-10 and IL-6 are associated with protection from neuro-inflammatory pathology. J Neuroimmunol. 2005;167(1-2):81-9.

14. Clark IA, Cowden WB, Butcher GA, Hunt NH. Possible roles of tumor necrosis factor in the pathology of malaria. Am J Pathol. 1987;129(1):192-9.

15. Clark IA, Rockett KA. The cytokine theory of human cerebral malaria. Parasitol Today. 1994;10(10):410-2.

16. Tuttolomondo A, Pecoraro R, Pinto A. Studies of selective TNF inhibitors in the treatment of brain injury from stroke and trauma: a review of the evidence to date. Drug Des Devel Ther. 2014;8:2221-38.

17. Pérez-Fuentes R, López-Colombo A, Ordóñez-Toquero G, Gomez-Albino I, Ramos J, Torres-Rasgado E, Salgado-Rosas H, Romero-Díaz M, Pulido-Pérez P, Sánchez-Guillén MC. Correlation of the serum concentrations of tumour necrosis factor and nitric oxide with disease severity in chronic Chagas disease (American trypanosomiasis). Ann Trop Med Parasitol. 2007;101(2): 123-32.

18. Pérez AR, Silva-Barbosa SD, Berbert LR, Revelli S, Beloscar J, Savino W, Bottasso O. Immunoneuroendocrine alterations in patients with progressive forms of chronic Chagas disease. J Neuroimmunol. 2011;235(1-2):84-90.

19. Pereira IR, Vilar-Pereira G, Silva AA, Lannes-Vieira J. Severity of chronic experimental Chagas' heart disease parallels tumour necrosis factor and nitric oxide levels in the serum: models of mild and severe disease. Mem Inst Oswaldo Cruz. 2014;109(3):289-98.

20. Villela E, Torres MC. Estudo histopatológico do sistema nervoso central em paralisis experimental determinada pelo S. cruzi. Mem Inst Oswaldo Cruz. 1926;19:175-98.

21. Pittella JE. Central nervous system involvement in Chagas' disease. An updating. Rev Inst Med Trop Sao Paulo. 1993;35(2):111-6.

22. Rocha A, Meneses AC, da Silva AM, Ferreira MS, Nishioka SA, Burgarelli MK, Almeida E, Turcato Júnior G, Metze K, Lopes ER. Pathology of patients with Chagas' disease and acquired immunodeficiency syndrome. Am J Trop Med Hyg. 1994;50(3):261-8

23. Antunes AC, Cecchini FM, Fv B, Oliveira PP, Reboucas RG, Monte TL, Fricke D. Cerebral trypanosomiasis and AIDS. Arq Neuropsiquiatr. 2002;60(3-B): 730-3.
24. Cordova E, Boschi A, Ambrosioni J, Cudos C, Corti M. Reactivation of Chagas disease with central nervous system involvement in HIV-infected patients in Argentina, 1992-2007. Int J Infect Dis. 2008;12(6):587-92.

25. Silva AA, Roffe E, Marino AP, dos Santos PV, Quirico-Santos T, Paiva CN, Lannes-Vieira J. Chagas' disease encephalitis: intense CD8+ lymphocytic infiltrate is restricted to the acute phase, but is not related to the presence of Trypanosoma cruzi antigens. Clin Immunol. 1999;92(1):56-66.

26. Da Mata JR, Camargos MR, Chiari E, Machado CR. Trypanosoma cruzi infection and the rat central nervous system: proliferation of parasites in astrocytes and the brain reaction to parasitism. Brain Res Bull. 2000;53(2):153-62.

27. Roffê E, Silva AA, Marino AP, dos Santos PV, Lannes-Vieira J. Essential role of VLA-4/NCAM-1 pathway in the establishment of CD8+ T-cell-mediated Trypanosoma cruzi-elicited meningoencephalitis. J Neuroimmunol. 2003; 142(1-2):17-30.

28. Vilar-Pereira G, Silva AA, Pereira IR, Silva RR, Moreira OC, de Almeida LR, de Souza AS, Rocha MS, Lannes-Vieira J. Trypanosoma cruzi-induced depressive like behavior Brain is independent of meningoencephalitis but responsive to parasiticide and TNF-targeted therapeutic interventions. Brain Behav Immun. 2012;26(7):1136-49.

29. Silva RR, Mariante RM, Silva AA, dos Santos AL, Roffê E, Santiago H, Gazzinelli RT, Lannes-Vieira J. Interferon-gamma promotes infection of astrocytes by Trypanosoma cruzi. PLoS One. 2015;19(10(2)):e0118600.

30. Ferreira MS, Nishioka SA, Silvestre MT, Borges AS, Nunes-Araújo FR, Rocha A. Reactivation of Chagas' disease in patients with AIDS: report of three new cases and review of the literature. Clin Infect Dis. 1997;25(6):1397-400.

31. Silva AA, Vilar-Pereira G, Souza AS, Silva RR, Rocha MS, Lannes-Vieira J. Trypanosoma cruzi-induced central nervous system alterations: from the entry of inflammatory cells to potential cognitive and psychiatric abnormalities. J Neuro-Oncol. 2010;1:1-13.

32. Fischer-Smith T, Bell C, Croul S, Lewis M, Rappaport J. Monocyte/ macrophage trafficking in acquired immunodeficiency syndrome encephalitis: lessons from human and nonhuman primate studies. J NeuroOncol. 2008;14(4):318-26.

33. Rozenfeld C, Martinez R, Figueiredo RT, Bozza MT, Lima FR, Pires AL, Silva PM, Bonomo A, Lannes-Vieira J, De Souza W, Moura-Neto V. Soluble factors released by Toxoplasma gondii-infected astrocytes down-modulate nitric oxide production by gamma interferon-activated microglia and prevent neuronal degeneration. Infect Immun. 2003;71(4):2047-57.

34. Zingales B, Andrade SG, Briones MRS, Campbell DA, Chiari E, Fer- Nandes O, Guhl F, Lages-Silva E, Macedo AM, Machado CR, Miles MA, Romanha AJ, Sturm NR, Tibayrenc M, Schijman AG. A new consensus for Trypanosoma cruzi intraspecific nomenclature: second revision meeting recommends $\mathrm{Tcl}$ to TcVI. Mem Inst Oswaldo Cruz. 2009;104(7):1051-4.

35. Mahmoud MF, El Shazly SM, Barakat W. Inhibition of TNF-a protects against hepatic ischemia-reperfusion injury in rats via NF-kB dependent pathway. Naunyn Schmiedeberg's Arch Pharmacol. 2012;385(5):465-71.

36. Pereira IR, Vilar-Pereira G, Moreira OC, Ramos IP, Gibaldi D, Britto C, Moraes MO, Lannes-Vieira J. Pentoxifylline reverses chronic experimental Chagasic cardiomyopathy in association with repositioning of abnormal CD8+ T-cell response. PLoS Negl Trop Dis. 2015;9(3):e0003659.

37. dos Santos PV, Roffê E, Santiago HC, Torres RA, Marino AP, Paiva CN, Silva AA, Gazzinelli RT, Lannes-Vieira J. Prevalence of CD8(+)alpha beta T cells in Trypanosoma cruzi-elicited myocarditis is associated with acquisition of CD62L(low)LFA-1(high)VLA-4(high) activation phenotype and expression of IFN-gamma-inducible adhesion and chemoattractant molecules. Microbes Infect. 2001;3(12):971-84.

38. Talvani A, Ribeiro CS, Aliberti JC, Michailowsky V, Santos PV, Murta SM, Romanha AJ, Almeida IC, Farber J, Lannes-Vieira J, Silva JS, Gazzinelli RT. Kinetics of cytokine gene expression in experimental chagasic cardiomyopathy: tissue parasitism and endogenous IFN-gamma as important determinants of chemokine mRNA expression during infection with Trypanosoma cruzi. Microbes Infect. 2000;2(8):851-66.

39. Redlich $K$, Hayer S, Maier A, Dunstan CR, Tohidast-Akrad M, Lang S, Türk B, Pietschmann P, Woloszczuk W, Haralambous S, Kollias G, Steiner G, Smolen JS, Schett G. Tumor necrosis factor alpha mediated joint destruction is inhibited by targeting osteoclasts with osteoprotegerin. Arthritis Rheum. 2002:46(3):785-92.

40. Pereira IR, Vilar-Pereira G, Silva AA, Moreira OC, Britto C, Sarmento ED, Lannes-Vieira J. Tumor necrosis factor is a therapeutic target for immunological unbalance and cardiac abnormalities in chronic experimental Chagas' heart disease. Mediators Inflamm. 2014;2014:798078. 
41. Hertz L. Calcium accumulation and calcium effects in astrocytes in primary cultures. Acta Physiol Scand Suppl. 1989;582:33.

42. Saura J. Microglial cells in astroglial cultures: a cautionary note. J Neuroinflammation. 2007:15(4):26-36.

43. Vargas-Zambrano JC, Lasso P, Cuellar A, Puerta CJ, González JM. A human astrocytoma cell line is highly susceptible to infection with Trypanosoma cruzi. Mem Inst Oswaldo Cruz. 2013;108(2):212-9.

44. Villela E, Villela C. Elementos do sistema nervosa central parasitados pelo $T$. cruzi. Mem Inst Oswaldo Cruz. 1932;26:77-82.

45. Hunter CA, Roberts CW, Alexander J. Kinetics of cytokine mRNA production in the brains of mice with progressive toxoplasmic encephalitis. Eur J Immunol. 1992;22(9):2317-22.

46. Medana IM, Hunt NH, Chaudhri G. Tumor necrosis factor-alpha expression in the brain during fatal murine cerebral malaria: evidence for production by microglia and astrocytes. Am J Pathol. 1997;150(4):1473-86.

47. Lannes-Vieira J, Pereira IR, Vinagre NF, Arnez LE. TNF- $a$ and TNFR in Chagas disease: from protective immunity to pathogenesis of chronic cardiomyopathy. Adv Exp Med Biol. 2011;691:221-30.

48. Starobinas N, Russo M, Minoprio P, Hontebeyrie-Joskowicz M. Is TNF alpha involved in early susceptibility of Trypanosoma cruzi-infected C3H/He mice? Res Immunol. 1991;142(2):117-22.

49. Pinto AM, Sales PC, Camargos ER, Silva AM. Tumour necrosis factor (TNF)mediated NF-KB activation facilitates cellular invasion of non-professional phagocytic epithelial cell lines by Trypanosoma cruzi. Cell Microbiol. 2011; 13(10):1518-29.

50. Black CM, Israelski DM, Suzuki Y, Remington JS. Effect of recombinant tumour necrosis factor on acute infection in mice with Toxoplasma gondii or Trypanosoma cruzi. Immunology. 1989;68(4):570-4

51. De Titto EH, Catterall JR, Remington JS. Activity of recombinant tumor necrosis factor on Toxoplasma gondii and Trypanosoma cruzi. J Immunol. 1986;137(4):1342-5.

52. Ming M, Ewen ME, Pereira ME. Trypanosome invasion of mammalian cells requires activation of the TGF beta signaling pathway. Cell. 1995;82(2):287-96.

53. Araújo-Jorge TC, Waghabi MC, Soeiro Mde N, Keramidas M, Bailly S, Feige JJ. Pivotal role for TGF-beta in infections heart disease: the case of Trypanosoma cruzi infection and consequent Chagasic myocardiopathy. Cytokine Growth Factor Rev. 2008:19(5-6):405-13.

54. Spooren A, Kolmus K, Laureys G, Clinckers R, De Keyser J, Haegeman G, Gerlo S. Interleukin-6, a mental cytokine. Brain Res Rev. 2011;67(1-2):157-83.

55. Savarin C, Hinton DR, Valentin-Torres A, Chen Z, Trapp BD, Bergmann CC, StohIman SA. Astrocyte response to IFN- $-\gamma$ limits IL-6-mediated microglia activation and progressive autoimmune encephalomyelitis. J Neuroinflammation. 2015;12:79.

56. Dantzer R, O'Connor JC, Freund GG, Johnson RW, Kelley KW. From inflammation to sickness and depression: when the immune system subjugates the brain. Nat Rev Neurosci. 2008:9(1):46-56.

57. Strieter RM, Remick DG, Ward PA, Spengler RN, Lynch JP 3rd, Larrick J, Kunkel SL. Cellular and molecular regulation of tumor necrosis factor-alpha production by pentoxifylline. Biochem Biophys Res Commun. 1988;155(3):1230-6.

58. Doherty GM, Jensen JC, Alexander HR, Buresh CM, Norton JA. Pentoxifylline suppression of tumor necrosis factor gene transcription. Surgery. 1991; 110(2):192-8.

59. Sliwa K, Woodiwiss A, Candy G, Badenhorst D, Libhaber C, Norton G, Skudicky D, Sareli P. Effects of pentoxifylline on cytokine profiles and left ventricular performance in patients with decompensated congestive heart failure secondary to idiopathic dilated cardiomyopathy. Am J Cardiol. 2002; 90(10):1118-22.

60. Hennessy E, Gormley S, Lopez-Rodriguez AB, Murray C, Murray C, Cunningham C. Systemic TNF-a produces acute cognitive dysfunction and exaggerated sickness behavior when superimposed upon progressive neurodegeneration. Brain, Behavior Immun. 2017:59:233-44.

\section{Submit your next manuscript to BioMed Central and we will help you at every step:}

- We accept pre-submission inquiries

- Our selector tool helps you to find the most relevant journal

- We provide round the clock customer support

- Convenient online submission

- Thorough peer review

- Inclusion in PubMed and all major indexing services

- Maximum visibility for your research

Submit your manuscript at www.biomedcentral.com/submit
Biomed Central 